\title{
RMetS
}

\section{Experimental assimilation of DIAL water vapour observations in the ECMWF global model}

\author{
F. Harnisch, ${ }^{\text {a*}}$ M. Weissmann, ${ }^{\mathrm{a}, \mathrm{b}}$ C. Cardinali ${ }^{\mathrm{c}}$ and M. Wirth ${ }^{\mathrm{a}}$ \\ ${ }^{a}$ Deutsches Zentrum für Luft- und Raumfahrt, Institut für Physik der Atmosphäre, Oberpfaffenhofen, Germany \\ ${ }^{\mathrm{b}}$ Meteorologisches Institut, Universität München, Germany \\ ${ }^{c}$ European Centre for Medium-Range Weather Forecasts, Reading, UK \\ ${ }^{\star}$ Correspondence to: F. Harnisch, Institut für Physik der Atmosphäre, DLR Oberpfaffenhofen, 82234 Wessling, Germany. \\ E-mail: Florian.Harnisch@dlr.de
}

\begin{abstract}
A unique airborne differential absorption lidar (DIAL) for water vapour observations was developed at the Deutsches Zentrum für Luft- und Raumfahrt (DLR). Installed on board the DLR Falcon 20 aircraft, the system measured a dataset of about 3900 water vapour profiles during the T-PARC field campaign. These highresolution humidity observations were assimilated into the European Centre for Medium-Range Weather Forecasts (ECMWF) global model using a version of the operational four-dimensional variational data assimilation system. The assimilation system is able to extract the information for DIAL observations, and verification with independent dropsonde observations shows a reduction in the analysis error when DIAL water vapour observations are assimilated. The forecast influence of the humidity observations is found to be small in most cases, but the observations are able to affect the forecast considerably under certain conditions. Systematic errors are investigated by comparison between humidity model fields, DIAL and dropsonde observations. Overall, DIAL observations are roughly 7-10\% drier than model fields throughout the troposphere. Comparison with dropsonde observations suggests that the DIAL observations are too dry in the lower troposphere but not above it. Copyright (c) 2011 Royal Meteorological Society
\end{abstract}

Key Words: T-PARC; observing system experiments; data assimilation

Received 2 December 2010; Revised 19 April 2011; Accepted 26 April 2011; Published online in Wiley Online Library 17 June 2011

Citation: Harnisch F, Weissmann M, Cardinali C, Wirth M. 2011. Experimental assimilation of DIAL water vapour observations in the ECMWF global model. Q. J. R. Meteorol. Soc. 137: 1532-1546. DOI:10.1002/qj.851

\section{Introduction}

Knowledge of global moisture distribution is an important ingredient for numerical weather prediction (NWP), especially for the forecast of precipitation (Ebert et al., 2003; Keil et al., 2008). In addition, water vapour affects the atmospheric radiation balance and can also be responsible for the transport of energy that is stored in evaporated water and released again by condensation (Pierrehumbert, 2002).

Nevertheless, the current observational network used for the initialization of NWP models is lacking sufficient accurate, vertically resolved observations of humidity.
The majority of atmospheric humidity observations are derived from passive satellite instruments such as the Atmospheric Infrared Sounder (AIRS), Advanced Microwave Sounding Unit (AMSU-A, AMSU-B) sounders, Infrared Atmospheric Sounding Interferometer (IASI), High Resolution Infrared Sounder (HIRS), Microwave Humidity Sounder (MHS), Advanced Microwave Scanning Radiometer (AMSR-E) or Special Sensor Microwave/Imager (SSM/I), which provide information on humidity indirectly by measuring radiances. Global positioning system (GPS) radio occultation techniques (Healy and Thépaut, 2006) and GPS ground-based measurements of slant total delay (Zus et al., 
2008) or zenith total delay (Poli et al., 2007) are another source of humidity information. High vertical resolution but poor horizontal and temporal coverage is achieved with radiosonde humidity observations, while ground stations provide observations near the surface.

The assimilation of humidity observations in NWP models is an active field of ongoing research. Bengtsson et al. (2004) found that the model is able to reproduce the hydrological cycle even without any humidity observations through the time evolution of wind, temperature and surface pressure using the European Centre for Medium-Range Weather Forecasts (ECMWF) $40 \mathrm{yr}$ reanalysis (ERA40) system. They further conducted forecast experiments showing the limited impact of humidity observations on the forecast skill of dynamical fields (Bengtsson and Hodges, 2005). In contrast, Andersson et al. (2007) demonstrated that the analysis and forecast of humidity, mass and wind fields of the ECMWF model benefits from humidity observations. They concluded that the ECMWF fourdimensional variational (4D-Var) data assimilation system and the improved formulation of the background error for humidity (Hólm et al., 2002) contributed to the positive results, whereas Bengtsson and Hodges (2005) used the less advanced ERA40 3D-Var system.

In recent years, active remote-sensing techniques such as differential absorption lidar (DIAL) systems were developed and tested during many field experiments. DIAL systems demonstrated an ability to supply precise humidity observations with high spatial and temporal resolution (Browell et al., 1998; Wulfmeyer and Bösenberg, 1998; Bruneau et al., 2001; Behrendt et al., 2007b; Kiemle et al., 2008). A detailed evaluation of different airborne water vapour DIAL systems was performed within the framework of the International $\mathrm{H}_{2} \mathrm{O}$ Project (IHOP_2002). The comparison of observations from ground-based lidar systems and different airborne DIAL systems showed an agreement, with interinstrumental biases smaller than $10 \%$ (Behrendt et al., 2007a,b). DIAL observations were also applied to derive latent-heat flux profiles for boundarylayer studies by using collocated wind observations (Kiemle et al., 2007). A case study demonstrated improvements in convective initiation and quantitative precipitation forecasts by assimilating Lidar Atmospheric Sensing Experiment (LASE) observations in a mesoscale model (Wulfmeyer et al., 2006). For forecasts of tropical cyclones using the Florida State University global spectral model, a beneficial influence was discovered with the assimilation of LASE humidity observations (Kamineni et al., 2003, 2006; Biswas and Krishnamurti, 2008).

All these previous studies were performed with twowavelength DIAL systems. In support of a mission proposal to the European Space Agency (ESA) for the Water Vapour Lidar Experiment in Space (WALES: Gérard et al., 2004), the first airborne four-wavelength DIAL was recently developed (Wirth et al., 2009) to investigate the feasibility of operating an active profiling DIAL system in space. The nadir-pointing WALES demonstrator was deployed during the Convective and Orographically-induced Precipitation Study (COPS) and the European THORPEX Regional Campaign (E-TReC) in 2007. These DIAL humidity observations were compared with ECMWF model fields of humidity (Schäfler et al., 2010) and were used in an intercomparison study with other lidar humidity observations (Bhawar et al., 2010).

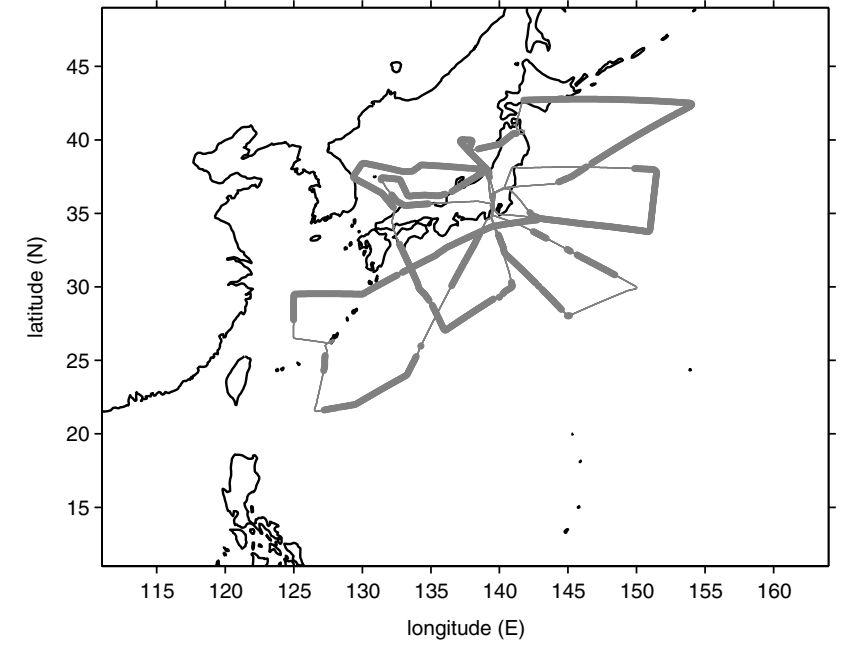

Figure 1. T-PARC flight tracks of the DLR Falcon (thin grey line) used for the study. Thick grey lines indicate the location of observed DIAL profiles.

The WALES demonstrator measured a unique dataset within the framework of the summer THORPEX Pacific Asian Regional Campaign (T-PARC) ${ }^{\dagger}$ which took place in the western North Pacific basin from August-October 2008. The aims of the campaign were to enhance our understanding of the short- and medium-range dynamics and the downstream impact of tropical cyclones in the western North Pacific as well as to improve the forecast skill of tropical cyclones. The nadir-pointing WALES demonstrator was installed on board the DLR Falcon aircraft based in Atsugi, Japan. A sample of about 3900 DIAL water vapour profiles was collected during 25 research flights during the period 26 August-1 October 2008. Additionally, a dropsonde system was installed on board the DLR Falcon.

This study focuses on the assimilation of the highresolution DIAL humidity observations into the ECMWF model using a version of the operational 4D-Var dataassimilation system. The quality of the observations is assessed by comparison with independent dropsonde humidity observations and model output fields. The analysis and forecast influence of the additional DIAL observations is evaluated.

Out of all flights during T-PARC, eight cases (Figure 1) that show the highest observational coverage and are representative of different weather regimes are selected for the study (Table I). These cases include flights for typhoon targeting and investigation of the extratropical transition (ET) of the two major typhoons during T-PARC, Sinlaku and Jangmi. Additionally, flights for the purpose of observation targeting to improve midlatitude forecasts or the observation of tropical water vapour export are considered. From these eight flights, 47700 DIAL observations are available, which constitutes $65 \%$ of DIAL observations from all 25 T-PARC flights.

The description of the DIAL system is given in section 2 and the assimilation set-up is described in section 3. General results are presented in section 4 followed by a case study in section 5. Section 6 discusses and summarizes the results.

${ }^{\dagger}$ http://www.eol.ucar.edu/projects/t-parc/ 
Table I. Overview of selected cases with DIAL observations. ET stands for extratropical transition.

\begin{tabular}{lllr}
\hline Case & Date & Objective & DIAL observations \\
\hline 1 & 0000 UTC 02 September & Midlatitude targeting & 6861 \\
2 & 0000 UTC 09 September & Tropical water vapour export & 3787 \\
3 & 1200 UTC 11 September & Targeting for Typhoon Sinlaku & 7190 \\
4 & E000 UTC 19 September & ET of Typhoon Sinlaku & 8537 \\
5 & 0000 UTC 21 September & ET of Typhoon Sinlaku & 7731 \\
6 & 0000 UTC 28 September & Targeting for Typhoon Jangmi & 3545 \\
7 & 0000 UTC 01 October & ET of Typhoon Jangmi (1) & 4737 \\
8 & 1200 UTC 01 October & ET of Typhoon Jangmi (2) & 5312 \\
\hline
\end{tabular}

\section{DIAL measurement system}

The active remote-sensing technique of a DIAL can be used to measure the concentration of various atmospheric trace gases such as water vapour, ozone, carbon dioxide, methane, etc. (Weitkamp, 2005). A DIAL system emits laser pulses at two distinct wavelengths, an on-line wavelength which is placed at an absorption line of the trace gas of interest and an off-line wavelength at a nearby non-absorbing wavelength. The concentration of the trace gas can be derived from the intensity difference of the backscatter signal received at the two wavelengths. A more detailed description of the DIAL measurement technique can be found in Ismail and Browell (1989) or Bösenberg (1998).

The WALES demonstrator uses two additional online wavelengths to enable a simultaneous coverage of measurements over the whole troposphere with high accuracy (Wirth et al., 2009). The three on-line wavelengths and one off-line wavelength are located within $0.6 \mathrm{~nm}$ in the $935 \mathrm{~nm}$ water vapour absorption band. There are different systematic and statistical error sources that can affect the DIAL observations (Poberaj et al., 2002). Systematic errors may originate from uncertainties related to the water vapour absorption-line parameters, the temperature dependence of the absorption cross section, the spectral purity of the laser and the stability of the on-line wavelength. However, it was shown that the error in the humidity observations can be expected to be less than 5-7\% (Kiemle et al., 2007; Bhawar et al., 2010).

One advantage of the nadir-pointing WALES demonstrator is the high spatial resolution of the observations. The horizontal resolution depends on the speed of the aircraft and ranges from $5-7 \mathrm{~km}$ for the T-PARC dataset. In the vertical, the raw data are processed with a resolution of $15 \mathrm{~m}$, but for humidity retrieval the resolution needs to be reduced to at least $290 \mathrm{~m}$ to fulfil precision requirements and provide vertically uncorrelated observations for data assimilation. The DIAL instrument is sensitive to clouds and cannot penetrate optically thick clouds or rain, which reduces the observational coverage in cloudy areas. Simultaneous atmospheric backscatter measurements at a wavelength of $1064 \mathrm{~nm}$ were used to determine lidar signals that were contaminated by clouds. Strict thresholds were applied to those signals and all DIAL observations below clouds were generally omitted to provide accurate observations.

\section{Set-up of assimilation experiments}

\subsection{The ECMWF Integrated Forecast System}

The assimilation experiments are performed using the early 2010 operational version of the ECMWF Integrated Forecast System (IFS) (cycle 36r1). In contrast to the operational set-up, the experiments are conducted using a reduced horizontal resolution of $T_{L} 799(\sim 25 \mathrm{~km})$ and 91 vertical levels (L91). The ECMWF data assimilation is a $4 \mathrm{D}-$ Var scheme with an incremental formulation of the cost function $J$ (Rabier et al., 2000):

$$
\begin{aligned}
& J\left[\delta \mathbf{x}\left(t_{0}\right)\right]=\frac{1}{2}\left[\delta \mathbf{x}\left(t_{0}\right)\right]^{\mathrm{T}} \mathbf{B}^{-1}\left[\delta \mathbf{x}\left(t_{0}\right)\right] \\
& \quad+\frac{1}{2} \sum_{i=0}^{n}\left[\mathbf{H}_{i} \delta \mathbf{x}\left(t_{i}\right)-\mathbf{d}_{i}\right]^{\mathrm{T}} \mathbf{R}_{i}^{-1}\left[\mathbf{H}_{i} \delta \mathbf{x}\left(t_{i}\right)-\mathbf{d}_{i}\right]
\end{aligned}
$$

with the increments at the initial time $\delta \mathbf{x}\left(t_{0}\right)=\mathbf{x}\left(t_{0}\right)$ $-\mathbf{x}^{\mathrm{b}}\left(t_{0}\right)$ formulated with respect to the model background state $\mathbf{x}^{\mathrm{b}}$ (generated from a short-term forecast). The subscript $i$ denotes the time index, with each $i$ corresponding to a half-hour time slot within the 12 hourly assimilation windows between 2100-0900 UTC and 0900-2100 UTC used for the nominal assimilation times at 0000 UTC and 1200 UTC, respectively. B is the background-error covariance matrix, whilst $\mathbf{R}_{i}$ is the observation-error covariance matrix at time $t_{i}$ and $\mathbf{H}_{i}$ is the linearized observation operator for the same time interval. The innovation vector $\mathbf{d}_{i}$, also called the background departure, is defined as

$$
\mathbf{d}_{i}=\mathbf{y}_{i}^{\mathrm{o}}-H_{i}\left[\mathbf{x}^{\mathrm{b}}\left(t_{i}\right)\right]
$$

for each time interval $i$ using the observations $\mathbf{y}_{i}^{o}$, the nonlinear observation operator $H_{i}$ and the time evolution of the model background state $\mathbf{x}^{\mathrm{b}}\left(t_{i}\right)=M_{i}\left[\mathbf{x}^{\mathrm{b}}\left(t_{0}\right)\right]$ with the high-resolution nonlinear forecast model $M_{i}$. The increments $\delta \mathbf{x}\left(t_{i}\right)=\mathbf{M}_{i} \delta \mathbf{x}\left(t_{0}\right)$ are evolved in time using a linearized version of the forecast model $\mathbf{M}_{i}$.

The incremental approach allows the use of different horizontal resolutions for the minimization of the cost function (Eq. (1)) and comparison of the observations with the model background state (Eq. (2)). At first, the innovation vector is computed by comparing the observations with the high-resolution nonlinear model state. The observation operator and the forecast model are linearized around the model background state. The minimization calculates the increment $\delta \mathbf{x}$ at a reduced model resolution using 
the linearized version of the forecast model (tangent linear model), the adjoint model and the linearized observation operator $\mathbf{H}_{i}$. The high-resolution nonlinear model state is updated with the computed increment $\delta \mathbf{x}$, the analysis is re-linearized and the next minimization is performed. In the current set-up, the nonlinear model runs at a resolution of $T_{L} 799 L 91$ and is updated three times by increments computed at resolutions of $T_{L} 95, T_{L} 159$ and $T_{L} 255$, respectively.

The background departure, that is the difference between observation and model background, is used for quality control of the observations (Järvinen and Undèn, 1997). In this background quality-control check (BgQC), likely wrong observations are rejected if the square of their background departure exceeds its expected variance by more than a predefined multiple of $\alpha$. Different flags are assigned for different values of $\alpha$ : flag 1 to 'probably correct' observations with $\alpha=3$, flag 2 to 'probably incorrect' observations with $\alpha=4$ and flag 3 to incorrect observations with $\alpha=5$. These thresholds for $\alpha$ are the same ones used for quality control of humidity observations in Järvinen and Undèn (1997). Only observations with flag 1 or without any flag are assimilated. To assure that a large percentage of DIAL observations actually enters the minimization process, the background-error variance has been changed to be twice as large as the observation-error variance.

During the minimization process, a variational quality control (VarQC) procedure (Andersson and Järvinen, 1999) is applied, where the cost function is modified by reducing the weight of the observations with large innovations. The VarQC procedure does not irrevocably reject observations and the weight of observations can change between different minimization steps.

For a more detailed description of the ECMWF assimilation system see Rabier et al. (2000), Bauer et al. (2010) and references therein.

\subsection{Precipitable water content}

The precipitable water content (PWC) in certain layers is used as input for the assimilation experiments, since an observation operator $H$ is already available (originally developed to assimilate data from the solar backscattering UV (SBUV) instrument). The DIAL system measures the number density of water molecules $N_{\mathrm{w}}\left[\mathrm{m}^{-3}\right]$, which is converted to absolute humidity $\rho_{\mathrm{w}}\left[\mathrm{kg} \mathrm{m}^{-3}\right]$ :

$$
\rho_{\mathrm{w}}=N_{\mathrm{w}} \frac{m_{\mathrm{H}_{2} \mathrm{O}}^{*}}{N_{\mathrm{A}}} \times 10^{-3},
$$

with the molecular mass of water $m_{\mathrm{H}_{2} \mathrm{O}}^{*}=18.015 \mathrm{~g} \mathrm{~mol}^{-1}$ and the Avogadro constant $N_{\mathrm{A}}=6.022 \times 10^{23} \mathrm{~mol}^{-1}$. No estimation of other parameters is needed to derive the variable, in contrast to e.g. specific humidity where additional temperature and pressure information is required (Behrendt et al., 2007a). Absolute humidity $\rho_{\mathrm{w}}$ is multiplied by the vertical resolution of the measurements to obtain vertically resolved profiles of PWC $\left[\mathrm{kg} \mathrm{m}^{-2}\right]$ :

$$
\operatorname{PWC}(z)=\rho_{\mathrm{w}} \Delta z .
$$

The sum of vertically resolved PWC over the whole atmosphere gives the total water column. PWC is a function of altitude and depends on the vertical resolution $\Delta z$ of the data. The DIAL data are averaged to a vertical resolution of $\Delta z=300 \mathrm{~m}$ for the assimilation experiments. The vertical coordinate is converted from geometric height to pressure using temperature, pressure and specific humidity from the operational ECMWF analysis.

\subsection{Experiments}

A control experiment (CNTL) is performed as a reference run that uses all operational but no DIAL observations. Over the northern West Pacific basin, humidity information is mainly provided by microwave sounding instruments (AMSU-B, MHS, SSM/I, AMSR-E) and infrared sounders (GOES, HIRS, AIRS and IASI) (Andersson et al., 2007; Bauer et al., 2011). Two experiments are conducted assimilating the DIAL observations together with the operational set of observations: ALL_DIAL with the full resolution of the DIAL observations, and AV_DIAL, in which five DIAL profiles are horizontally averaged. With the given horizontal resolution of the measurements of $5-7 \mathrm{~km}$, averaging five profiles produces a spatial scale similar to the ECMWF model $(\sim 25 \mathrm{~km})$. In all experiments, dropsonde observations are not assimilated, first to avoid interaction between dropsonde and collocated DIAL humidity observations and second so they may be used as independent validation of the DIAL observations. The experiments using DIAL observations are performed in an uncycled mode with the model background for each assimilation cycle being provided by CNTL, which restricts the influence of the DIAL observations to one particular assimilation time.

\subsection{Error specification}

The instrument error of the DIAL can be estimated to be $<5-7 \%$ (Poberaj et al., 2002; Wirth et al., 2009). In ALL_DIAL, the observation-error standard deviation is set to $40 \%$ to account also for the representativeness error. The observation-error standard deviation is proportional to $1 / \sqrt{N_{\text {obs }}}$ assuming that the observation errors are independent, which reduces the observation-error standard deviation to $\sim 15 \%$ at a grid-box length-scale, given the horizontal resolution of the observations of $5-7 \mathrm{~km}$. Hence, an error standard deviation of $15 \%$ is assigned to the observations in AV_DIAL, where the observations are averaged to the model resolution (see Table II).

\section{Results}

\subsection{Comparison of DIAL and dropsonde observations}

During all T-PARC Falcon flights, dropsondes of the type Vaisala RD-93 (Hock and Franklin, 1999) were deployed at regular intervals. The observations are compared with DIAL observations, whenever they are available within a circle of $5 \mathrm{~km}$ radius from the dropsonde launch position. The DIAL system measures the number of water molecules per volume $N_{\mathrm{w}}$, which is converted into absolute humidity $\rho_{\mathrm{w}}$ using Eq. (3). The dropsonde system measures pressure, temperature $(T)$ and relative humidity $(f)$, and the absolute humidity is computed using

$$
\rho_{\mathrm{w}}=\frac{e}{R_{\mathrm{w}} T}=\frac{e_{\mathrm{s}}(T) f}{R_{\mathrm{w}} T},
$$


Table II. Number of DIAL observations marked during the different observation quality-control steps. For the assimilation, only observations that achieve a VarQC weight larger than $25 \%$ are considered: ALL_DIAL $=45$ 571, AV_DIAL $=7454$.

\begin{tabular}{|c|c|c|c|c|c|c|c|c|c|c|}
\hline \multirow[b]{2}{*}{ Exp } & \multicolumn{2}{|c|}{ Observation } & \multicolumn{4}{|c|}{ BgQC flag } & \multicolumn{4}{|c|}{ VarQC weight (\%) class } \\
\hline & number & error & 0 & 1 & 2 & 3 & $0-25$ & $25-50$ & $50-75$ & $>75$ \\
\hline ALL_DIAL & 47700 & $40 \%$ & 45967 & 488 & 320 & 925 & 884 & 803 & 9989 & 34779 \\
\hline AV_DIAL & 9524 & $15 \%$ & 8492 & 318 & 160 & 554 & 1256 & 653 & 2884 & 3917 \\
\hline
\end{tabular}

Italic fonts indicate that the observations are regarded as 'false'.

with the gas constant for water vapour $\left(R_{\mathrm{w}}=\right.$ $\left.461 \mathrm{~J} \mathrm{~K}^{-1} \mathrm{~kg}^{-1}\right)$ and applying the Clausius-Clapeyron equation (see e.g. Bohren and Albrecht, 1998) to calculate the saturation water vapour pressure $e_{S}(T)$. The dropsonde observations are quality-controlled using different post-processing methods, including automatic sounding quality-control software and visual examination of the data (Wang et al., 2010).

DIAL and dropsonde profiles are vertically averaged to a resolution of $25 \mathrm{~m}$, which is slightly larger than the raw vertical resolution of dropsonde (5-10 m) and DIAL (15 m) observations, to create homogeneous height bins for the comparison of the two datasets. However, the presented results are not sensitive to the choice of height interval used. Considering all the T-PARC flights of the DLR Falcon, 39410 data points from 157 collocated profiles are used for the comparison. Note that the evaluated dropsonde and DIAL observations are collected between 0730 and 2100 local time (Japan Standard Time), since DLR Falcon flights are performed during daytime. Figure 2(a) shows a linear relation (correlation coefficient 0.987 ) between DIAL and dropsonde absolute humidity observations. The comparison of individual profiles also shows a good agreement between the two observations, as demonstrated in Figure 2(b) and (c).

The absolute humidity difference is defined in absolute values as

$$
d_{-} \rho_{\mathrm{w}, \mathrm{abs}}=\rho_{\mathrm{w}, \mathrm{dial}}-\rho_{\mathrm{w}, \mathrm{drop}},
$$

and in relative values as

$$
d_{-} \rho_{\mathrm{w}, \text { rel }}=\frac{\rho_{\mathrm{w}, \text { dial }}-\rho_{\mathrm{w}, \mathrm{drop}}}{0.5\left(\rho_{\mathrm{w}, \mathrm{dial}}+\rho_{\mathrm{w}, \mathrm{drop}}\right)} .
$$

The relative differences take into account the strong altitude dependence of moisture. The mean value (bias) of absolute and relative differences is calculated for all height intervals (Figure 3(a) and (b)). Negative values indicate that the DIAL observations are drier than the dropsonde observations. In terms of bias of absolute differences (Figure 3(a)), observations from both instruments are in agreement in the upper troposphere, whilst in the lower troposphere the absolute bias is negative below $5 \mathrm{~km}$ (above mean sea level) and increases up to $-1 \mathrm{~g} \mathrm{~m}^{-3}$ at the ground. The relative bias reaches values between $-5 \%$ and $-10 \%$ below $2 \mathrm{~km}$. In contrast to the absolute bias, the relative bias (mean relative difference) is close to zero between 2 and $5 \mathrm{~km}$ (Figure 3(b)). In addition, a median and the lower and upper quartiles of the relative differences are shown in Figure 3(b). The smaller relative bias (than absolute bias) is presumably due to outliers, as the values in several layers are close to the upper quartile of relative differences in the range
$2-7 \mathrm{~km}$. The $1000 \mathrm{~m}$ running average of the relative median also shows negative values in the range $2-5 \mathrm{~km}$, which is in better agreement with the absolute bias.

A mismatch between the location of dropsonde and DIAL observations might produce a larger standard deviation in the differences between the two observations (Sun et al., 2010), but should not result in an increased bias. The identified systematic differences between dropsonde and DIAL observations in the lower part of the troposphere seem mainly to be caused by DIAL observations, since dropsonde observations were shown to be largely unbiased (Wang, 2005). However, a dropsonde bias in the range of several percent cannot be excluded. Larger errors in DIAL observations can occur in the tropical boundary layer and the lower part of the troposphere (Poberaj et al., 2002). Due to the high water vapour content in the Tropics, a very weak water vapour absorption line located at $935.449 \mathrm{~nm}$ wavelength (see figure 1 in Wirth et al., 2009) had to be selected to probe the lowest part of the atmosphere. The total absorption at this wavelength is affected by the pressure-broadened wings of nearby strong absorption lines. Both pressure-broadening by air molecules and self-broadening by water vapour are taken into account during processing, but the accuracy of the absorption crosssections calculated from the line parameters given by the HITRAN 2006 spectroscopic database at these extremely high humidity values is not sufficiently known and may reach values in the range of the observed bias. The bias of all data is in absolute terms $-0.142 \mathrm{~g} \mathrm{~m}^{-3}$ with a standard deviation of $\pm 0.636 \mathrm{~g} \mathrm{~m}^{-3}$ and in relative terms $0.0 \%$ with a standard deviation of $\pm 30.7 \%$. Only daytime observations are analyzed and no diurnal signal in the bias is identified.

\subsection{Assimilation statistics of the DIAL experiments}

The numbers of observations identified by the different screening steps of the assimilation system are summarized in Table II. In ALL_DIAL, more than $97 \%$ of the observations pass the $\mathrm{BgQC}$ and enter the assimilation procedure classified as 'correct' or 'probably correct' observations (flags 0 and 1), while in AV_DIAL the rejection rate is slightly higher and $92.5 \%$ pass the BgQC. These numbers seem reasonable taking into account the smaller observationerror variances assigned in AV_DIAL. Similarly, 98\% of the observations in ALL_DIAL are considered as 'correct' in the VarQC (weight larger than 25\%) compared with $85 \%$ of the observations in AV_DIAL. The quality control is more active for AV_DIAL compared with ALL_DIAL. The observationerror standard deviation of $15 \%$ in AV_DIAL, which is based on the assumption of independent observation errors, may be too small. This is also indicated by the diagnosed observation-error standard deviations of $28 \%$ for ALL_DIAL and $21 \%$ for AV_DIAL calculated a posteriori from the 

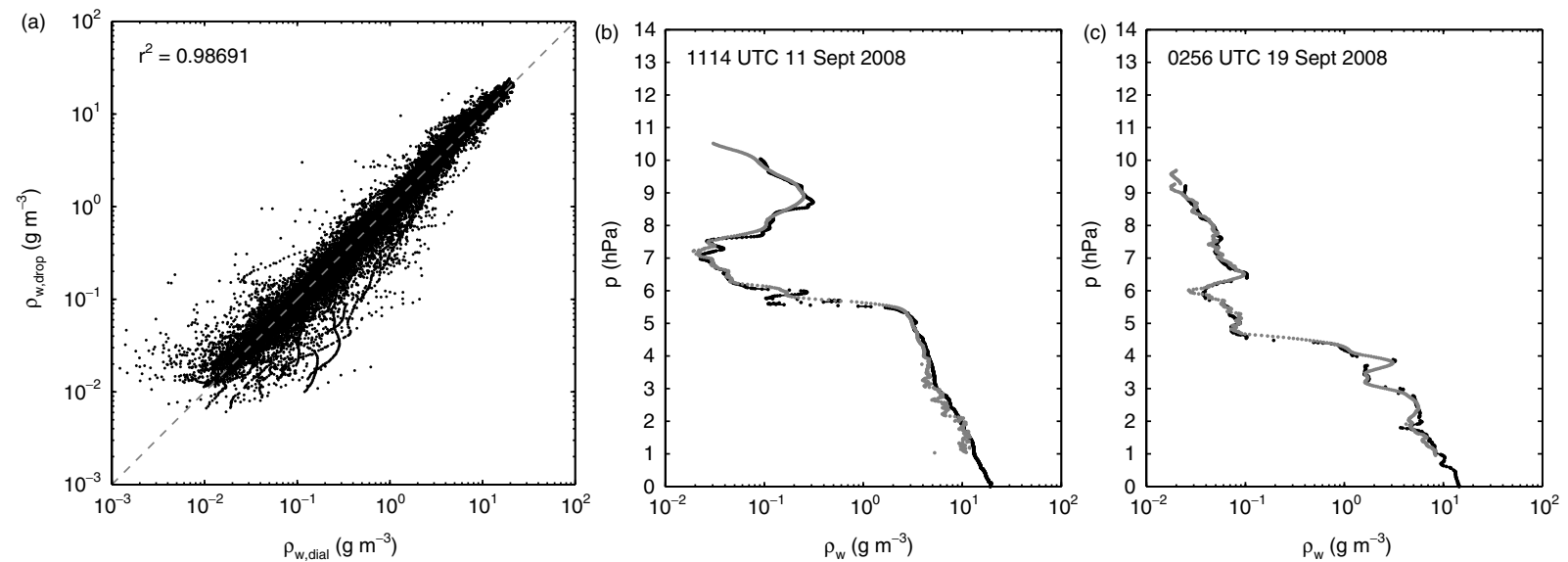

Figure 2. Comparison of DIAL and dropsonde observations of absolute humidity: (a) scatter plot of all 39410 observations between 26 August and 1 October 2008 and (b), (c) two selected DIAL (grey) and dropsonde (black) profiles.
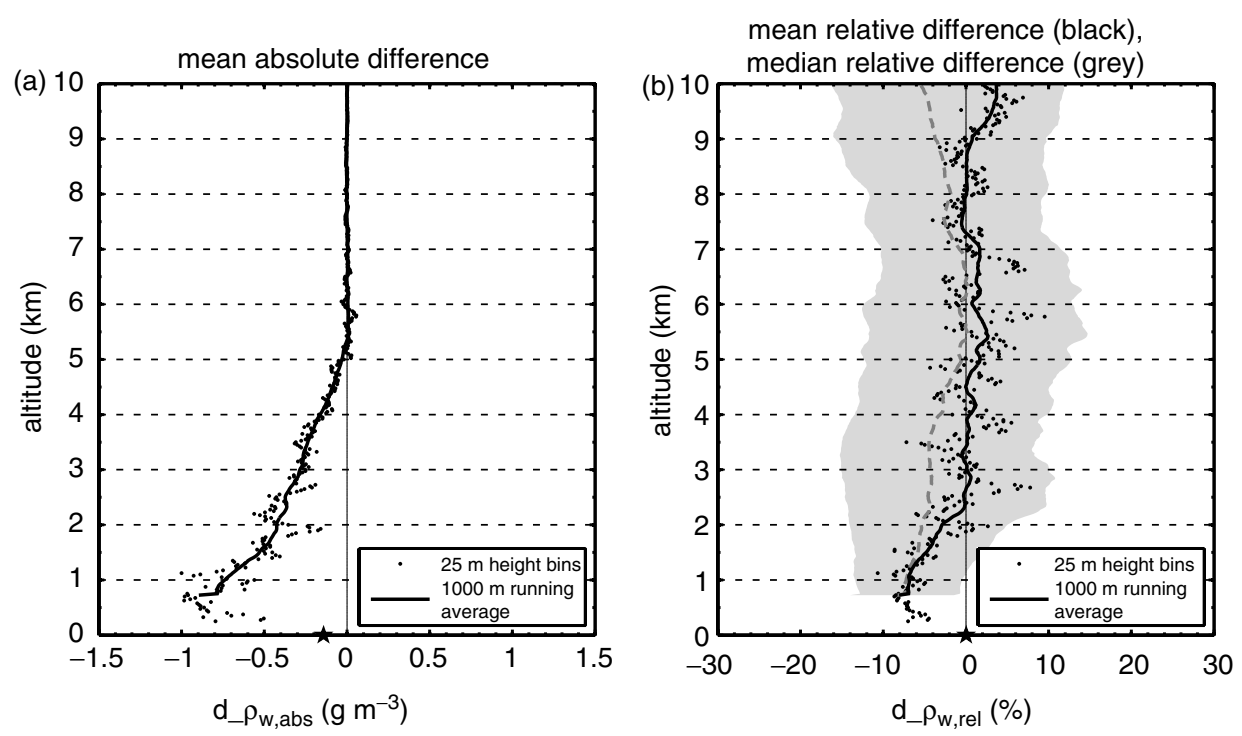

Figure 3. Vertical distribution of (a) mean absolute and (b) mean relative differences between DIAL and dropsonde observations of absolute humidity for the same dataset as in Figure 2(a). The solid black line represents a $1000 \mathrm{~m}$ running average and the asterisk marks the overall bias of all observations. In (b) the dashed grey line displays the $1000 \mathrm{~m}$ running average of the median of the relative differences and the grey shading the lower and upper quartiles of the relative differences.

assimilation statistics following Desroziers et al. (2005). This difference of observation-error standard deviations might result from the identified systematic error in the DIAL observations and a possible correlation of the representativeness error at the horizontal resolution of 5-7 km of the DIAL observations.

The background and analysis departures are the difference in observation space between observation and model background and observation and analysis, respectively:

$$
\begin{aligned}
& \text { d_bg }=\mathbf{y}_{\mathrm{o}}-H\left[\mathbf{x}^{\mathrm{b}}\right], \\
& \mathbf{d}_{-} \mathrm{an}=\mathbf{y}_{\mathrm{o}}-H\left[\mathbf{x}^{\mathrm{a}}\right] .
\end{aligned}
$$

The bias and the standard deviation for the background and analysis departures of absolute humidity for ALL_DIAL are shown in Figure 4. Absolute humidity is derived from PWC dividing by the vertical resolution $\Delta z=300 \mathrm{~m}$ (Eq. (4)). A negative bias of background departures is seen in the lower troposphere with maximum values close to $-1 \mathrm{~g} \mathrm{~m}^{-3}$
(Figure 4(a)). The bias of the analysis departures is much smaller and close to zero except in the boundary-layer region. The standard deviation of analysis departures is also reduced compared with the background value, which indicates that the assimilation is using information from DIAL observations and that the observations actively contribute to the analysis (Figure 4(b)). To include the decrease of water vapour with height, relative background and analysis departures are defined as the absolute departure value divided by the mean value of observation and model fields. A much more homogeneous distribution in the vertical is identified for the bias of these relative departures (Figure 4(c)). The bias of the relative background departures varies between -5 and $-15 \%$ over the whole troposphere, while the bias of the relative analysis departures is less than $5 \%$, with negative values below $775 \mathrm{hPa}$ and positive ones above (Figure 4(c)). The standard deviation of the relative departures reaches a maximum in the upper troposphere (Figure 4(d)), different from the absolute standard deviation which peaks around $850 \mathrm{hPa}$. The sample available reduces rapidly at lower 

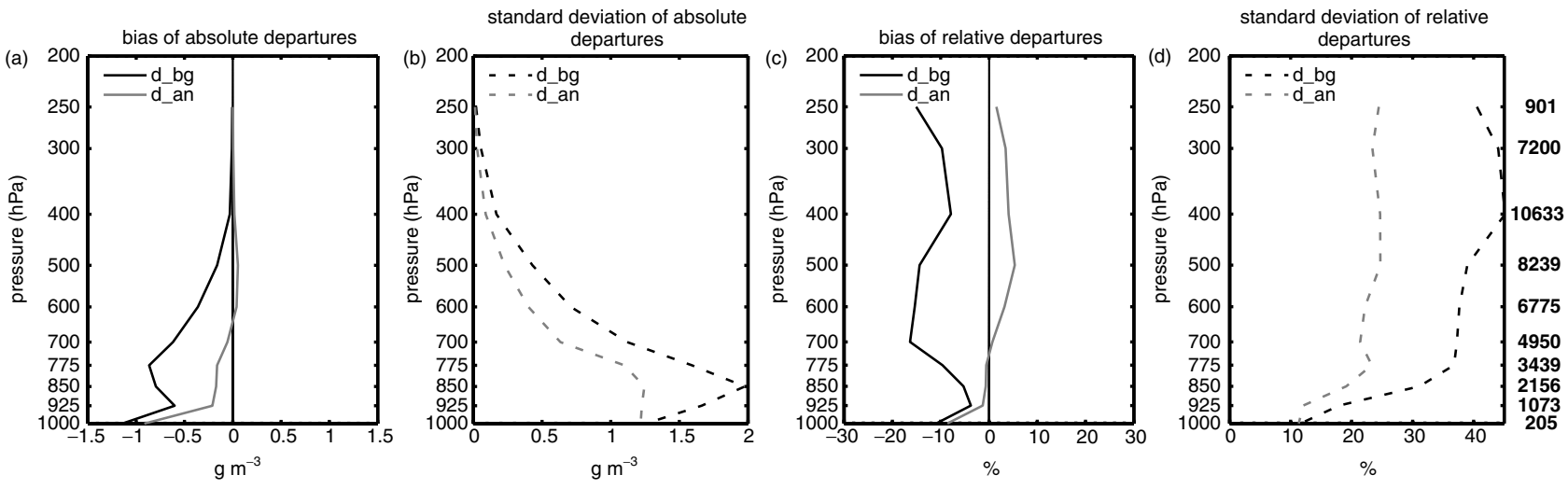

Figure 4. Vertical distribution of background departures d_bg (black) and analysis departures d_an (grey) for DIAL observations in ALL_DIAL: (a) absolute bias, (b) absolute standard deviation, (c) relative bias and (d) relative standard deviation. Only data that passed the BgQC and get a weight of at least 25\% in the VarQC are considered. The number of DIAL observations considered for each pressure interval is displayed to the right.

Table III. Bias and standard deviation (stddev) of DIAL absolute humidity observation departures.

\begin{tabular}{lcrrr}
\hline & \multicolumn{2}{c}{ Abs bias $\pm \operatorname{stddev}\left(\mathrm{g} \mathrm{m}^{-3}\right)$} & \multicolumn{2}{c}{ Rel bias \pm stddev $(\%)$} \\
Exp & d_ bg & d_ an & d_ bg & d_ an \\
\hline ALL_DIAL & $-0.281 \pm 0.888$ & $-0.015 \pm 0.543$ & $-11.4 \pm 40.2$ & $2.9 \pm 23.2$ \\
AV_DIAL & $-0.242 \pm 0.773$ & $-0.036 \pm 0.423$ & $-7.1 \pm 30.0$ & $0.7 \pm 13.4$ \\
\hline
\end{tabular}

levels. The results for AV_DIAL are similar overall, but with smaller biases and standard deviations (not shown).

Table III summarizes the bias and standard deviation (stddev) for both experiments. The negative bias between the observations and the model background indicates that the model is systematically moister than the DIAL observations. The moisture in the model fields is reduced when the DIAL observations are assimilated, as shown by the analysis departures.

\subsection{Analysis impact}

\subsubsection{Analysis verification with dropsondes}

The DIAL analysis impact is verified using independent dropsonde humidity observations, which are monitored passively, i.e. do not influence the analysis. These observations are the best available source of humidity information, since other observing systems such as for example satellite humidity observations have poor effective vertical resolution in the troposphere. CNTL, ALL_DIAL and AV_DIAL analyses are compared in terms of root-mean-square (RMS) differences from the dropsonde observations. The smaller RMS differences of ALL_DIAL and AV_DIAL indicate a more accurate analysis. Regarding the absolute humidity analysis, RMS differences are, on average, smaller in ALL_DIAL $\left(1.11 \mathrm{~g} \mathrm{~m}^{-3}\right)$ and AV_DIAL $\left(1.14 \mathrm{~g} \mathrm{~m}^{-3}\right)$ than in CNTL $\left(1.20 \mathrm{~g} \mathrm{~m}^{-3}\right)$, which is equivalent to an accuracy increase with respect to CNTL of $7.5 \%$ and $5 \%$, respectively (Figure 5(a)). In two cases, the DIAL experiments show slightly larger RMS differences compared with CNTL, whereas in four cases smaller values are seen. For wind and temperature variables, RMS differences for the DIAL experiments are also reduced compared with CNTL by the order of 2-3\% (not shown).

Background and analysis departures of dropsonde observations are also used to analyse systematic errors. The bias of absolute humidity dropsonde observation departures for ALL_DIAL and CNTL is shown in Figure 5(b). The bias of dropsonde background departures is negative for all levels above $850 \mathrm{hPa}$, similar to the background departures of DIAL observations (compare also with Figure 4(a)). This suggests that the model background is systematically too moist, as dropsonde and DIAL observations match in the upper and middle troposphere (compare with Figure 3(b)). In the lower troposphere, the bias of dropsonde background departures is smaller and becomes positive in the boundary layer (Figure 5(b)). The different behaviour of dropsonde and DIAL background departures at low levels agrees with the systematic difference between the two observations at those levels (Figure 3). Using the bias of the background departures of dropsonde $\left(-0.158 \mathrm{~g} \mathrm{~m}^{-3}\right.$; Figure $\left.5(\mathrm{~b})\right)$ and DIAL $\left(-0.281 \mathrm{~g} \mathrm{~m}^{-3}\right.$; Table III) observations, the bias of the difference between DIAL and dropsonde observations can be calculated $\left(-0.123 \mathrm{~g} \mathrm{~m}^{-3}\right)$. This value is similar to the one computed for all available DIAL and dropsonde observations $\left(-0.142 \mathrm{~g} \mathrm{~m}^{-3}\right)$, despite the difference in vertical resolution and sample, which implies that the bias between dropsonde and DIAL observations is not sensitive to the vertical resolution and the sample used. The fact that the bias of dropsonde analysis departures is positive in ALL_DIAL, compared with a negative bias in CNTL, illustrates the drying effect of DIAL observations (Figure 5(b)).

\subsubsection{Analysis influence}

The analysis departures of satellite and radiosonde humidity observations are not much affected by the assimilation of DIAL humidity observations. For the DIAL experiments, the Degree of Freedom for Signal (DFS) is calculated, which estimates the information content provided by the observations during the assimilation (Cardinali et al., 2004). The DFS depends on the influence of the observations as well as on the number of observations. Table IV lists the estimated DFS and mean observation influence from 

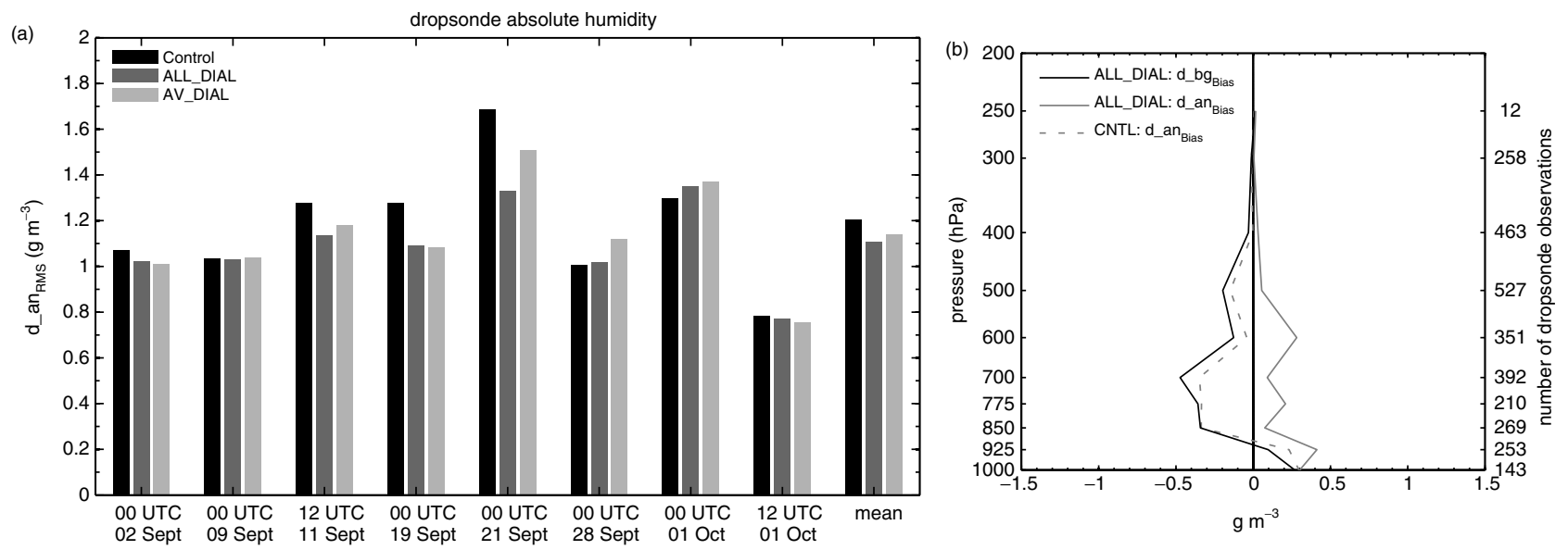

Figure 5. (a) Root mean square (RMS) of the differences of dropsonde absolute humidity observations and the model analysis of CNTL, ALL_DIAL and AV_DIAL in $\mathrm{g} \mathrm{m}^{-3}$. (b) Vertical distribution of absolute bias of background departures (d_bg) and analysis departures (d_an) for dropsonde absolute humidity compared with ALL_DIAL and CNTL. Note that the background departures are the same for ALL_DIAL and CNTL. The number of dropsonde observations considered for each pressure interval is displayed to the right.

all satellite, radiosonde and DIAL humidity observations. DIAL observations have the largest influence among all other remote sensing and radiosonde humidity observations, which confirms the strong influence of adaptive DIAL observations in the humidity analysis with respect to the other humidity observations.

Additionally, the influence of the DIAL observations on the analysis is shown based on analysis increments of total column water vapour (TCWV). TCWV is an integrative measure of the water vapour in the atmosphere and is strongly determined by the lowest part of the troposphere, which contains most of the water vapour. Figure 6 shows the mean TCWV increments averaged over all cases for CNTL and the difference of the mean increments between ALL_DIAL and CNTL at the beginning of the assimilation window (either 09 UTC or 21 UTC). The increments of CNTL exhibit positive and negative areas, which indicates that the assimilation system is not systematically adding or removing water vapour. The difference of the increments between ALL_DIAL and CNTL shows broad regions with negative values, leading to more negative TCWV increments when using the DIAL observations. The drying effect of the DIAL observations is in agreement with the previous diagnostic assessment, which shows that DIAL observations, on average, are drier than the model background and close to the model analysis after assimilation. Mean analysis increments for wind and temperature (not shown) are noisy and not systematic. The analysis increments of AV_DIAL (not shown) are similar to those of ALL_DIAL.

\subsection{Forecast impact}

The forecast impact of the DIAL observations is addressed in terms of total energy (TE). TE is an integrated measure of the forecast error and includes information about wind $(u, v)$, temperature $(T)$ and specific humidity $(q)$ fields. The improvement or reduction of the TE error is defined as the difference of the TE error of the DIAL experiments against the control experiment, with negative values indicating improvement by assimilating DIAL observations (see Appendix A for a definition).

Figure 7 displays the TE error reduction of AV_DIAL with respect to CNTL averaged over a geographical domain covering the northern West Pacific basin $\left(15^{\circ}-60^{\circ} \mathrm{N}\right.$, $\left.115^{\circ} \mathrm{E}-160^{\circ} \mathrm{W}\right)$ for all eight cases. In most cases, the values are small and range from $-1.5 \mathrm{~m}^{2} \mathrm{~s}^{-2}$ to $+1.5 \mathrm{~m}^{2} \mathrm{~s}^{-2}$, but improvements up to $-4 \mathrm{~m}^{2} \mathrm{~s}^{-2}$ are identified for the forecasts initialized on 19 and 21 September. The relative differences of AV_DIAL and CNTL are generally in the range of $\pm 2 \%$, except for the +48 and $+60 \mathrm{~h}$ lead times of forecasts initialized on 19 and 21 September, which show improvements up to $-6 \%$. Results for ALL_DIAL (not shown) are similar to those for AV_DIAL, but with slightly smaller improvements.

Three research flights were conducted during the lifetime of Typhoon Sinlaku (Table I: case 2, 3,4) and one during Typhoon Jangmi (Table I: case 6). For these cases, the typhoon track forecast of the DIAL experiments is evaluated using storm positions of the Japanese Meteorological Agency best-track data. The influence of the DIAL observations is small and the mean track forecast errors of ALL_DIAL and AV_DIAL are similar to those for CNTL (not shown). The reason for this low influence may be that, due to signal absorption in clouds, the nadir-pointing DIAL cannot provide information on water vapour in the convectively active environment of the storm, which would likely be more influential on the dynamical evolution of the system.

\section{Case study: 19 September 2008}

Out of the eight cases, 19 September 2008 is selected for a detailed case study due to the large influence of DIAL observations compared with the other cases.

The objectives of the flight were to examine the ridgebuilding that was triggered by the outflow of Typhoon Sinlaku and the interaction of the storm with the midlatitude jet (Figure 8(a)). At analysis time, Typhoon Sinlaku is located at about $134^{\circ} \mathrm{E}, 32.5^{\circ} \mathrm{N}$ close to the south coast of the main island of Japan. The flight track starts at the jet entrance region at the northern tip of Japan (Figure 8(a), labels 1, 2 ), continues eastwards along the jet streak (label 3) and cuts through the jet maximum on the way back (label 4). The flight track is also partially located in sensitive regions calculated by ECMWF singular vectors that are optimized for a verification region over the western North Pacific 48 hours later (not shown). The TCWV field shows a sharp 
Table IV. Mean observation influence (OI) and Degree of Freedom for Signal (DFS) for DIAL, satellite and radiosonde (TEMP) humidity observations in ALL_DIAL over the western North Pacific basin $\left(15^{\circ}-55^{\circ} \mathrm{N}, 110^{\circ} \mathrm{E}-160^{\circ} \mathrm{E}\right)$.

\begin{tabular}{lccccccccc}
\hline & DIAL & HIRS & MTSAT & AMSU-B & MHS & AMSR-E & SSM/I & MERIS & TEMP \\
\hline Mean OI & 0.71 & 0.07 & 0.16 & 0.04 & 0.13 & 0.01 & 0.002 & 0.16 & 0.16 \\
Observation number & 46455 & 89766 & 29192 & 90675 & 16617 & 85494 & 74307 & 640 & 9775 \\
DFS & 32957.0 & 5935.8 & 4803.2 & 3848.5 & 2114.2 & 544.0 & 211.1 & 102.7 & 1527.9 \\
DFS in \% of total & 63.3 & 11.4 & 9.2 & 7.4 & 4.1 & 1.0 & 0.4 & 0.2 & 2.9 \\
\hline
\end{tabular}
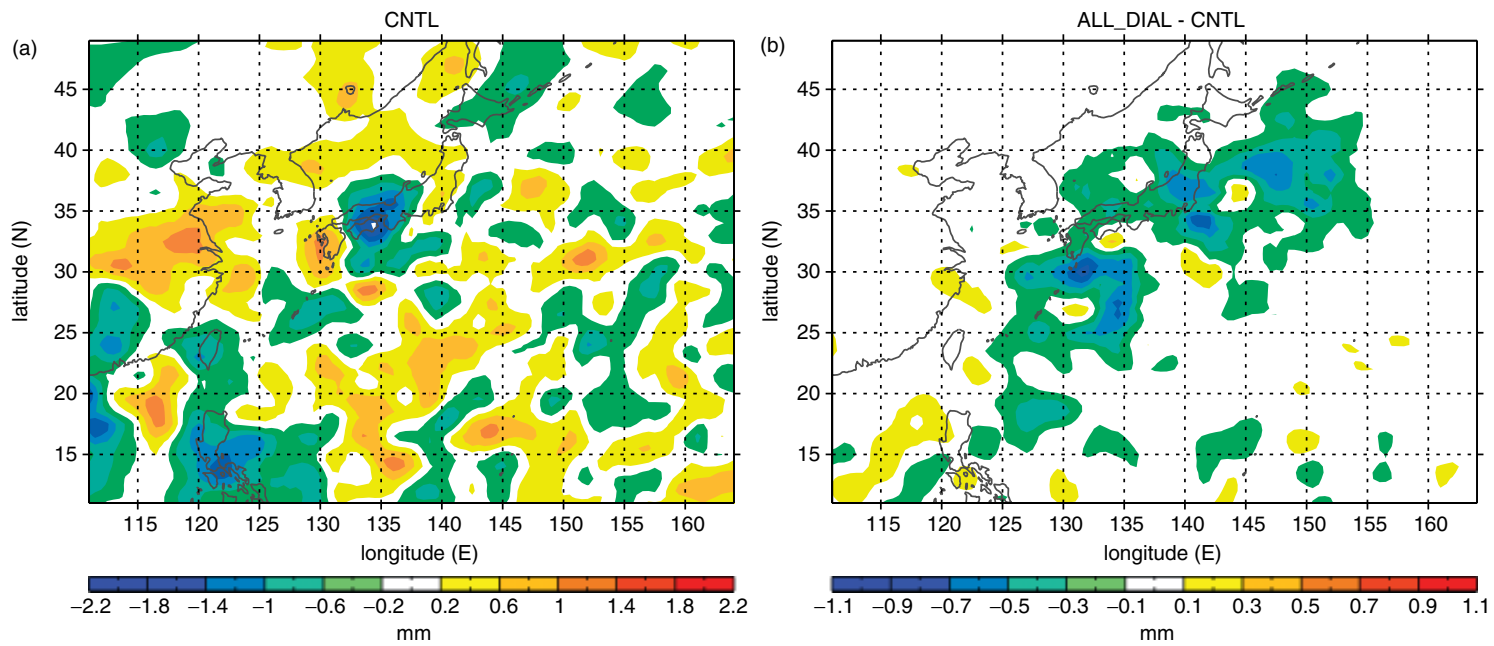

Figure 6. Mean analysis increments of total column water vapour (TCWV) for the selected eight cases of (a) CNTL and (b) the difference between the mean increments of ALL_DIAL and CNTL in mm.

north-south gradient to the east of Japan, which is partially crossed on the last flight leg (Figure 8(a)). A tongue of moist air $(28 \mathrm{~mm} \leq$ TCWV $\leq 34 \mathrm{~mm})$ extends further to the north and is located downstream of an approaching trough.

The height-distance transect of DIAL observations is shown in Figure 8(b). In the first third of the flight (labels 1, 2), PWC values greater than $1.5 \mathrm{~kg} \mathrm{~m}^{-2}$ are observed in the lower troposphere up to $775 \mathrm{hPa}$. Further to the east, the layer of large PWC values increases its vertical extension and the upper boundary reaches $600 \mathrm{hPa}$ next to the easternmost point of the flight track (label 3). The moist layer shows vertical as well as horizontal fluctuations. The vertical extent of the moist layer is reduced to $700 \mathrm{hPa}$ on the flight leg back to Japan. During the end of the flight track (label 4), the aircraft enters a region with strong convective activity and a pronounced vertical transport of moisture from the ground up to $350 \mathrm{hPa}$ is identified. The observational gaps (white regions in the transects) are caused by the full absorption of the lidar signal in clouds. Figure 8(c) shows the same transect as Figure 8(b), but analysis increments of PWC for AV_DIAL. Negative analysis increments occur in the moist layer close to the ground for most of the transect, which indicates a drying effect of the DIAL observations on the analysis in this region. However, at the jet entrance region (label 2) the DIAL observations lead to an increase of moisture at $700 \mathrm{hPa}$ in a region with a less pronounced vertical moisture gradient. The vertical transport of moisture at the end of the flight track (label 4) is influenced by DIAL
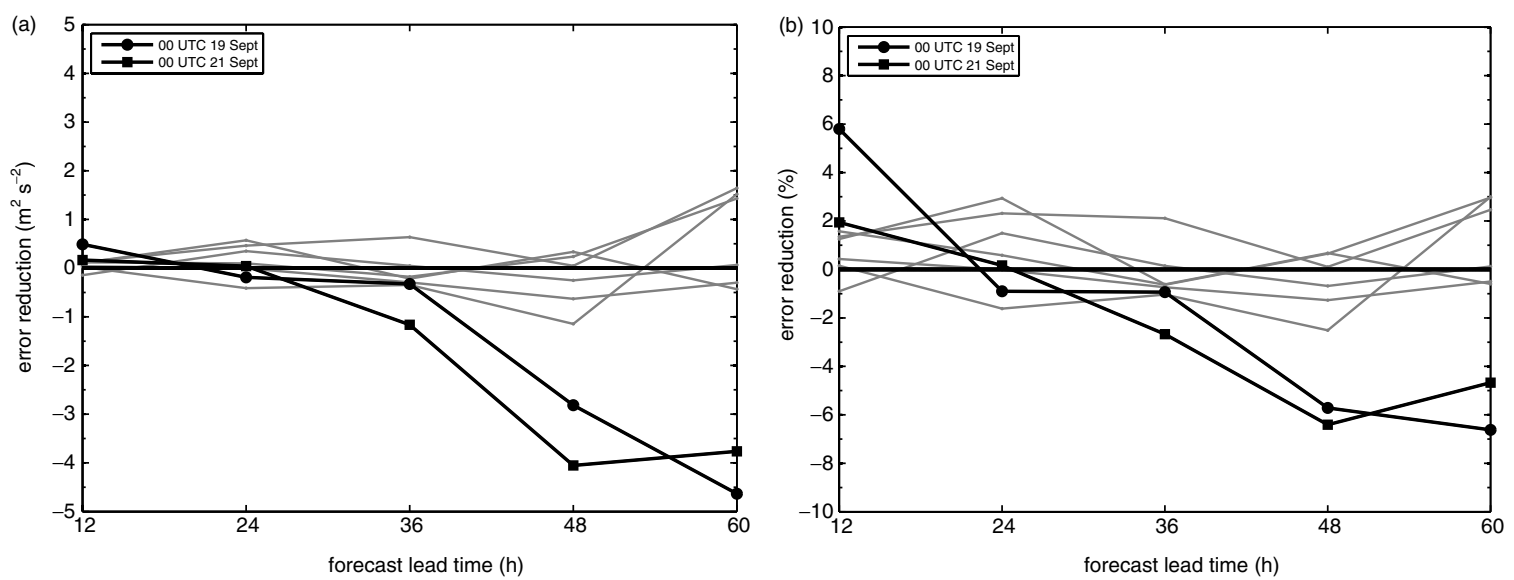

Figure 7. (a) Absolute and (b) relative reduction of TE forecast error for AV_DIAL compared with CNTL over the western North Pacific basin $\left(15^{\circ}-60^{\circ}\right.$ N, $\left.115^{\circ} \mathrm{E}-160^{\circ} \mathrm{W}\right)$. Grey lines represent the six cases with small forecast impact. The forecasts are verified with the CNTL analysis. Negative values indicate reduced errors of AV_DIAL. 

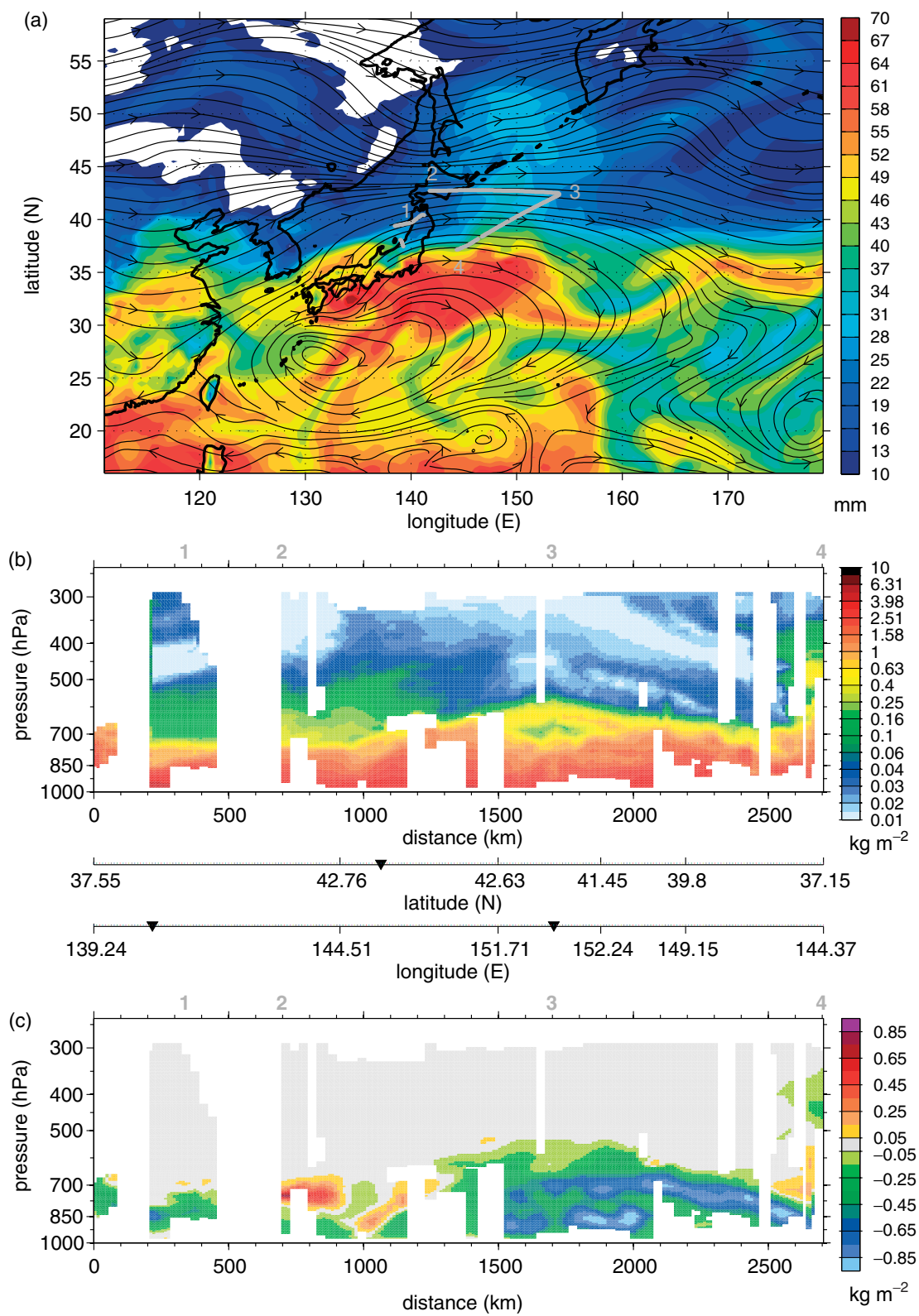

Figure 8. (a) Streamlines at $200 \mathrm{hPa}$ and TCWV for the CNTL analysis at 0000 UTC on 19 September. The direction of the flight track (grey line) is clockwise. Height-distance transect of (b) DIAL PWC observations and (c) PWC analysis increments of AV_DIAL for the 0000 UTC 19 September assimilation time sampled between 2257 UTC on 18 September and 0436 UTC on 19 September. Bold grey numbers label different sections of the flight track.

observations, and an increase of moisture is seen in the layer between 775 and $550 \mathrm{hPa}$, followed by a decrease above $500 \mathrm{hPa}$.

Analysis differences of absolute humidity at $850 \mathrm{hPa}$ between AV_DIAL and CNTL (Figure 9(a)) are related to the area of moist air extending to the north and to the gradient of moisture east of Japan, where AV_DIAL is drier than CNTL, as expected from the analysis increments (compare with Figure 8(c)). In the region east of Typhoon Sinlaku, AV_DIAL also shows areas with higher moisture content at low levels. At $+12 \mathrm{~h}$ forecast lead time, the differences between AV_DIAL and CNTL are transported downstream to the east and stretch from Sinlaku to another low-pressure system over the central North Pacific (Figure 9(b)). In addition, a broad region of negative forecast differences is seen downstream of the trough centred over the Sea of Okhotsk and the Kamchatka Peninsula, where the AV_DIAL forecast is generally drier than the CNTL forecast. This humidity difference affects the geopotential height and wind fields at $500 \mathrm{hPa}$ next to the intensifying trough and a less intense system is forecast in AV_DIAL at $+24 \mathrm{~h}$ (Figure 10(a)). From +24 h onwards, humidity differences do not grow much in amplitude but instead change their structure and become inhomogeneous, with alternating positive and negative areas (Figure 9(c)). Higher values of moisture in AV_DIAL are located west of ex-Sinlaku at $+48 \mathrm{~h}$ (Figure 9(d)) and forecast differences also spread to the east and polewards. The development of the trough is modified and a less pronounced system, which is shifted further to the south, is seen in the AV_DIAL forecast (Figure 10(b)).

The TE error of the AV_DIAL forecast is reduced compared with the CNTL forecast from +24 to $+60 \mathrm{~h}$ (Figure 7). The signal in the TE error is related to the region where the largest humidity and geopotential differences are found (Figure 11), but also noise that is not directly linked to the observation influence starts to appear further 

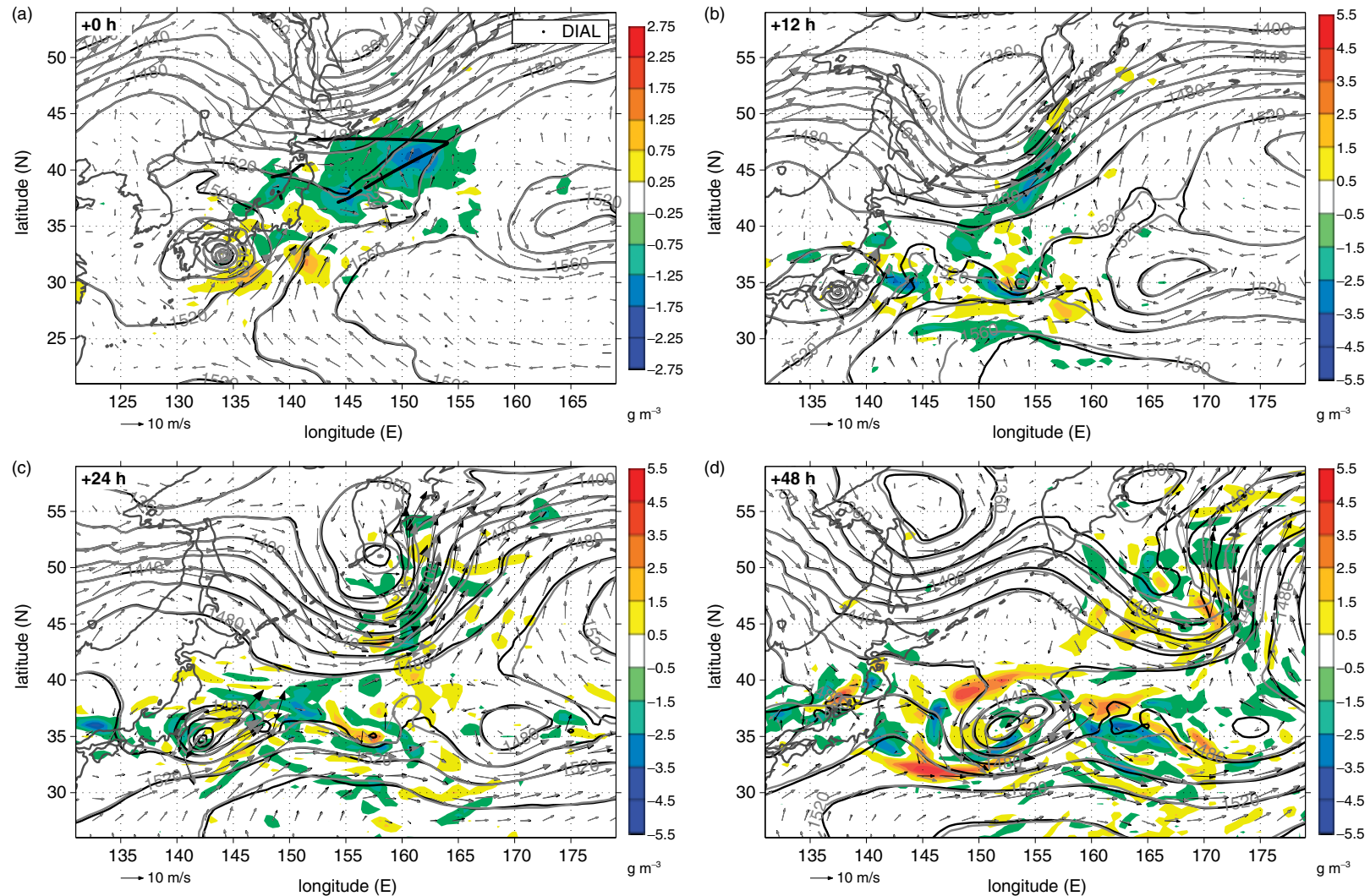

Figure 9. Absolute humidity difference $\left(\mathrm{g} \mathrm{m}^{-3}\right)$ at $850 \mathrm{hPa}$ between AV_DIAL and CNTL for (a) the analysis at $0000 \mathrm{UTC}$ on 19 September and (b) $+12 \mathrm{~h}$, (c) $+24 \mathrm{~h}$ and $(\mathrm{d})+48 \mathrm{~h}$ forecasts initialized at $0000 \mathrm{UTC}$ on 19 September. Lines (arrows) represent the geopotential height (wind field) at $850 \mathrm{hPa}$ : AV_DIAL is shown in black and CNTL in grey. Note the different colour scaling in (a).
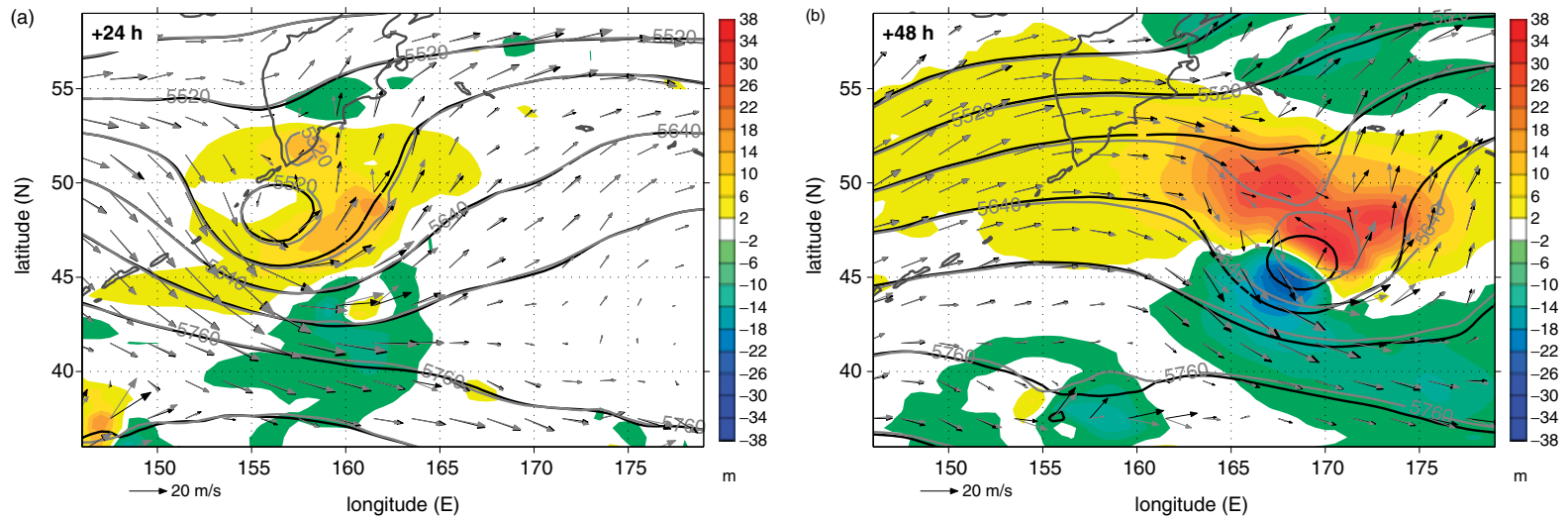

Figure 10. Forecast difference of geopotential height $(\mathrm{m})$ at $500 \mathrm{hPa}$ between AV_DIAL and CNTL for (a) $+24 \mathrm{~h}$ and (b) $+48 \mathrm{~h}$ forecasts initialized at 0000 UTC on 19 September. Lines (arrows) represent the geopotential height (wind field) at 500 hPa: AV_DIAL is shown in black and CNTL in grey.

to the south. The differences of TE error close to exSinlaku and the trough to the north grow strongest and at $+48 \mathrm{~h}$ a clear $\mathrm{TE}$ error reduction of the AV_DIAL forecast is seen related to the poleward trough. The changes of humidity, geopotential and wind field of the trough, caused by the initial changes in the moisture distribution of AV_DIAL (Figure 9(a)), are reducing the TE error of the AV_DIAL forecast considerably (Figure 11(d)). Note that the evolution on 21 September 2008 (Figure 11), the second case with a clear positive forecast impact, is similar, but the modification of the humidity analysis connected with the remnants of Sinlaku is more important for forecast improvements.

Changes in the moisture analysis also affect the precipitation forecast. The accumulated 12 hourly rainfall forecasts from ALL_DIAL, AV_DIAL and CNTL, as well as the rainfall product derived from Tropical Rainfall Measurement Mission (TRMM) data (3B42 V6), are displayed in Figure 12. The rainfall forecast of the experiments generally looks reasonable and agrees with the TRMM observations. Larger differences occur at the eastern side of Typhoon Sinlaku around $34^{\circ} \mathrm{N}, 142.5^{\circ} \mathrm{E}$, where the precipitation forecast of AV_DIAL seems to fit the TRMM-based data best, while no distinct differences between forecasts are found in other regions.

\section{Discussion and summary}

A large dataset of about 40000 high-resolution humidity observations measured by a four-wavelength DIAL system 

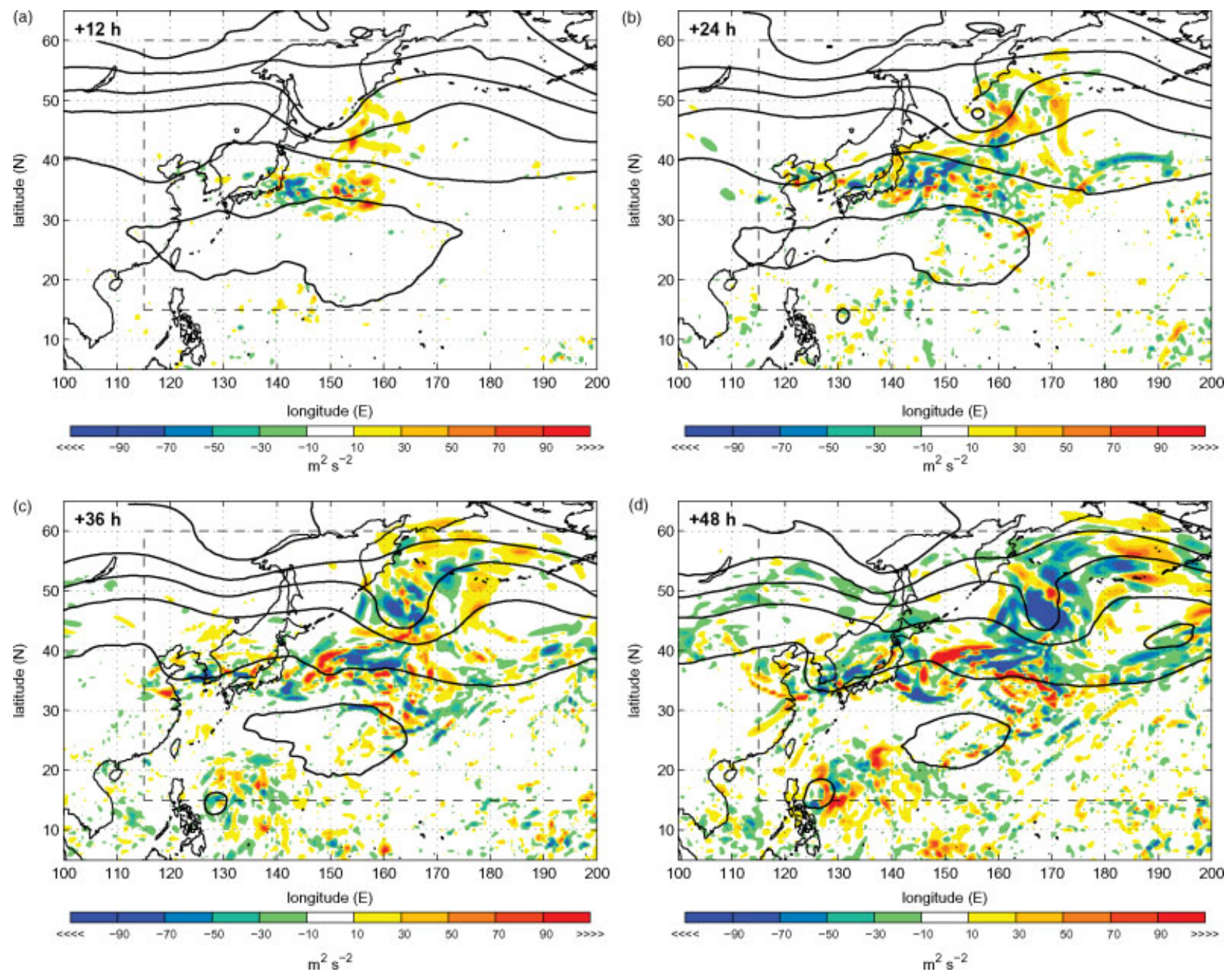

Figure 11. Geographical maps of TE forecast error reduction $\left(\mathrm{m}^{2} \mathrm{~s}^{-2}\right)$ for the AV_DIAL experiment compared with the CNTL run for (a) $+12 \mathrm{~h}$, (b) $+24 \mathrm{~h},(\mathrm{c})+36 \mathrm{~h}$ and (d) $+48 \mathrm{~h}$ forecasts initialized at 0000 UTC on 19 September. The forecasts are verified with the CNTL analysis. The analysis of $500 \mathrm{hPa}$ geopotential height of the CNTL experiment is shown as a solid line and the geographical domain used for the averaging of the TE improvement as a dashed line.

installed on board the DLR Falcon aircraft is assimilated into the ECMWF global model using a version of the operational $4 \mathrm{D}$-Var assimilation system.

A detailed comparison of the DIAL observations with dropsonde humidity observations is performed. Single profiles of both observing systems show good agreement. Moist layers and sharp gradients are represented correctly. In the statistical comparison, a bias between DIAL and dropsonde observations is found, especially in the lower troposphere, where DIAL observations are drier than the dropsondes. The overall bias of absolute humidity is $-0.142 \mathrm{~g} \mathrm{~m}^{-3}$. While the overall relative bias is less than $-0.01 \%$, a relative dry bias of $\sim-4.2 \%$ is seen from the ground up to $3 \mathrm{~km}$. This value is comparable to results from an intercomparison study during COPS, when a dry bias of the DLR DIAL system of $-2.23 \%$ was found compared with other water vapour lidar observations (Bhawar et al., 2010). Larger errors of the DIAL system close to the ground may result from the selected weak water vapour absorption line leading to reduced accuracy.

The assimilation of DIAL observations enables the comparison of model output fields and observations against each other. Background and analysis departures are directly calculated in the assimilation system, which minimizes interpolation errors because no additional interpolation steps are needed, as in the previous studies of Flentje et al. (2007) and Schäfler et al. (2010). Using all DIAL observations from eight selected cases, a bias between the model background (i.e. short-range model forecast) and the observations of $-0.281 \mathrm{~g} \mathrm{~m}^{-3}(-11.4 \%)$ is found, with the model background being moister than the observations. The relative bias against the model background is consistent at all heights and confirms the findings of Flentje et al. (2007) and Schäfler et al. (2010), who discovered a bias in the range of $0-11 \%$ and $17.1 \%$, respectively. These studies considered single flights located in different regions of the globe, while this study uses a larger dataset within the same geographical region. Dropsondes also show a negative bias against the model background in the middle and upper troposphere, similar to the DIAL observations. This suggests a moist model bias in these layers. In the lower troposphere, dropsondes indicate a dry bias of DIAL observations.

DIAL observations can only be made in cloud-free regions, as lidar systems operate in the visible and near-infrared spectra and cannot penetrate optically thick clouds or rain. This inhomogeneous distribution of water vapour observations may also contribute to the identified bias of the DIAL observations. Previous work suggests that the ECMWF model in rainy or non-rainy areas can have opposite humidity biases of $5-10 \%$ of total column water 

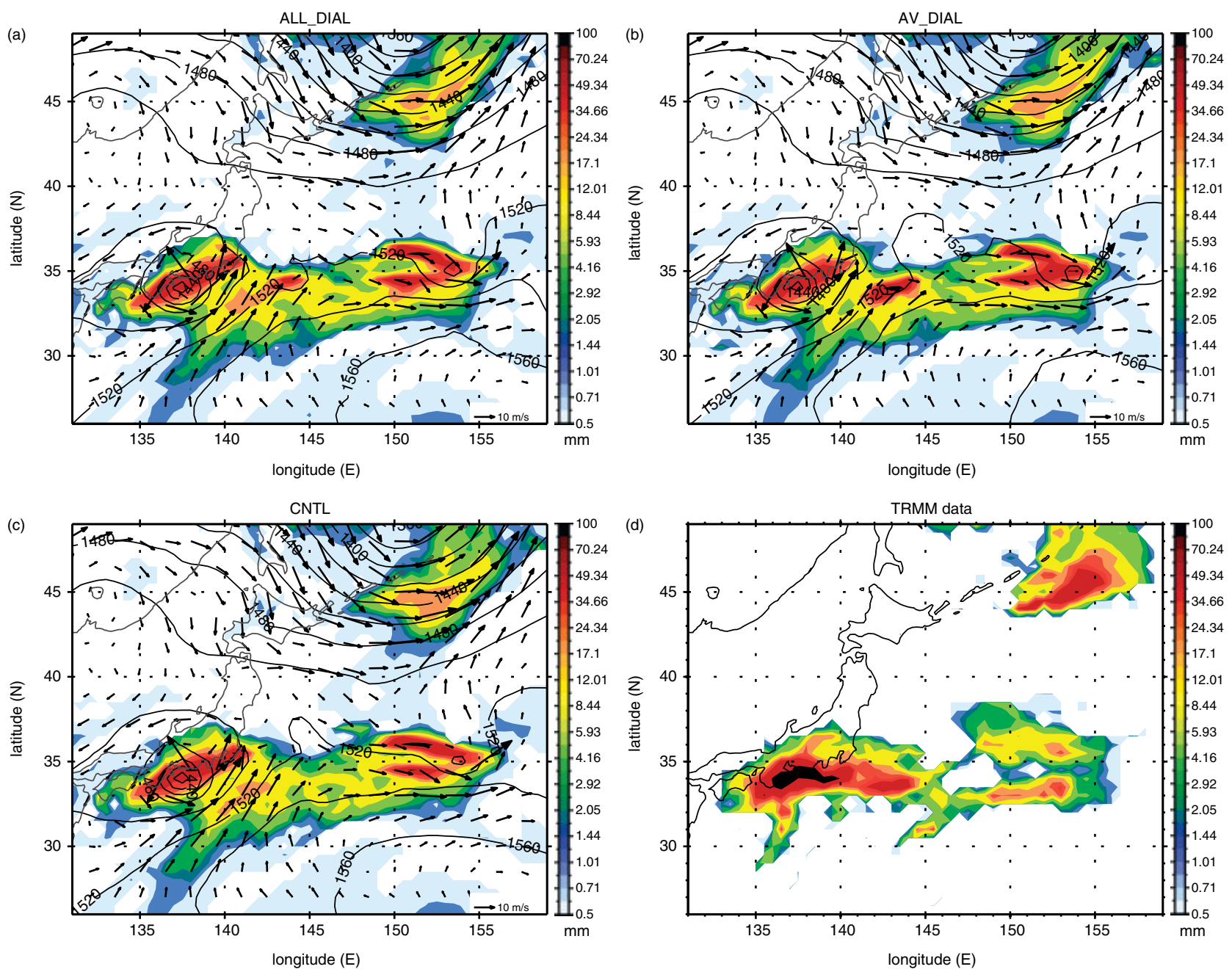

Figure 12. $+12 \mathrm{~h}$ forecast of 12 hourly rainfall (colour shading), geopotential height (black line) and wind field (black arrows) at 850 hPa initialized at 0000 UTC on 19 September for (a) ALL_DIAL, (b) AV_DIAL and (c) CNTL. (d) The 12 hourly rainfall derived from the Tropical Rainfall Measuring Mission (TRMM) data (3B42 V6).

vapour (Marécal et al., 2001, 2002). When satellite humidity data were only used in rain-free conditions, extrapolation of information into rainy areas often degraded the analysis by increasing the bias (Andersson et al., 2005).

The DFS of DIAL is the largest, in comparison with radiosonde and satellite humidity observations. On average, DIAL observations reduce the moisture content of the analysis. The accuracy of the analysis of ALL_DIAL, AV_DIAL and CNTL is evaluated using independent dropsonde humidity observations. On average, the RMS differences between these dropsonde observations and ALL_DIAL and AV_DIAL analyses are reduced by $7.5 \%$ and $5 \%$, respectively, compared with CNTL analyses.

In general, a smaller forecast influence of humidity observations compared with pressure, wind or temperature is expected whenever diabatic processes do not affect the model dynamics explicitly and are not important for the forecast. In the experiments performed, DIAL observations only lead to a clear positive forecast impact in two out of eight cases, whereas the influence in the other six cases is less than $\pm 2 \%$. The observing system experiments in Bengtsson and Hodges (2005) and Andersson et al. (2007) denied either a subset of humidity observations or all humidity observations completely. In contrast, the experiments in this study use the operational observational network with a few million observations each day plus a limited set of additional DIAL observations ( $\sim 3500-8500$ per day). Even when using all additional T-PARC dropsonde observations (wind, temperature and humidity), a limited impact on midlatitude forecasts in the ECMWF was found, in particular with the uncycled set-up (Weissmann et al., 2010). A cycled experiment that assimilates all DIAL observations was also performed within this study. However, no results of the cycled experiment are shown; the assimilation statistics of DIAL and other humidity observations are very similar, the forecast influence is comparable to that of the uncycled ALL_DIAL experiment and the influence of the DIAL observations is easier to track in the uncycled case.

In some cases, changes to the moisture fields can affect the dynamics considerably, as seen on 19 September 2008. DIAL observations modify the humidity analysis at an apparently sensitive region of a distinct north-south humidity gradient and next to a tongue of moist air extending polewards to a developing midlatitude low-pressure system. These changes of the humidity influence the forecast, leading to a reduction of the TE forecast error up to $-6 \%$ from $+24 \mathrm{~h}$ onwards.

The tropical cyclone (TC) track forecast is not affected significantly by the DIAL observations, in contrast to previous studies with LASE data (Kamineni et al., 2006; Biswas and Krishnamurti, 2008). The smaller influence on TC track forecasts is likely related to the fact that the LASE data studies apply a different assimilation procedure and use 
the Florida State University global spectral model, whereas this study uses the operational ECMWF model system with millions of satellite data assimilated. Other studies also documented that the influence of additional observations on TC forecasts strongly depends on the assimilation and forecasting system (e.g. Weissmann et al., 2010; Chou et al., 2010).

DIAL observations are taken in cloud-free regions, whilst convectively active and baroclinically unstable regions, where the moisture distribution plays an important role due to diabatic processes, are often covered by clouds. A high correlation between the location of clouds and meteorologically sensitive areas calculated using adjoint techniques was found by McNally (2002), which highlights the importance of observations in cloudy and rainy regions.

DIAL observations are assimilated with the full horizontal resolution (ALL_DIAL) but also averaged to grid-box scale (AV_DIAL). Results from both experiments are similar, but the averaging set-up seems to be more suitable, as the bias is reduced and the forecast improvement is larger. Currently, the ECMWF 4D-Var analysis is computed at a resolution of $T_{L} 255(\sim 80 \mathrm{~km})$, which limits the influence of observations with finer resolution. Nevertheless, spatial high-resolution DIAL observations are potentially valuable for mesoscale models, which have a horizontal model resolution similar to that of the observations and can resolve diabatic processes such as convection explicitly. For future assimilation experiments, the introduction of a bias correction of DIAL data may help to optimize the influence of the DIAL humidity observations, since variational assimilation methods assume unbiased observations.

\section{Acknowledgements}

The data were collected as part of T-PARC. The DLR Falcon aircraft was sponsored by an international consortium from Germany (DLR, Forschungszentrum Karlsruhe), the United States (National Science Foundation), Japan (Japan Meteorological Agency), Korea (National Institute of Meteorological Research) and Canada (Environment Canada). The role of the United States Navy and the National Center for Atmospheric Research's Earth Observing Laboratory (NCAR EOL) for campaign and data management is acknowledged.

The support of various people at ECMWF for the experiments and ECMWF computing resources are greatly appreciated. In particular, the authors acknowledge the help of Peter Bauer, Rosanna Dragani, Anne Fouilloux and Elias Hólm. This work is part of the Deutsche Forschungsgemeinschaft (German Research Foundation) research unit Predictability and Dynamics of Weather Systems in the Atlantic-European Sector (PANDOWAE; more information is available online at http://www.pandowae.de).

The TRMM data used in this study were acquired using the GES-DISC Interactive Online Visualization ANd aNalysis Infrastructure (Giovanni) as part of the NASA Goddard Earth Sciences (GES) Data and Information Services Center (DISC).

The authors thank three anonymous reviewers for their valuable comments on the manuscript.

\section{A. Appendix: Computing the total energy (TE)}

The total energy (TE) error $\left(\mathrm{m}^{2} \mathrm{~s}^{-2}\right)$ of the forecast is defined as

$$
\begin{aligned}
T E_{\mathrm{F}-\mathrm{A}} & =\frac{1}{2}\left[\left(u_{\mathrm{F}}-u_{\mathrm{A}}\right)^{2}+\left(v_{\mathrm{F}}-v_{\mathrm{A}}\right)^{2}\right] \\
+ & \frac{1}{2} \frac{c_{\mathrm{p}}}{T_{\text {ref }}}\left(T_{\mathrm{F}}-T_{\mathrm{A}}\right)^{2}+\frac{1}{2} \frac{L^{2}}{c_{\mathrm{p}} T_{\mathrm{ref}}}\left(q_{\mathrm{F}}-q_{\mathrm{A}}\right)^{2},
\end{aligned}
$$

with reference temperature $T_{\text {ref }}=300 \mathrm{~K}$, specific heat at constant pressure $c_{\mathrm{p}}=1004.7 \mathrm{~J} \mathrm{~kg}^{-1} \mathrm{~K}^{-1}$ and latent heat of condensation $L=2.51 \times 10^{6} \mathrm{~J} \mathrm{~kg}^{-1}$. The subscript $\mathrm{F}$ denotes the forecast and the subscript $\mathrm{A}$ the analysis fields. The calculation of $\mathrm{TE}_{\mathrm{F}-\mathrm{A}}$ is done at 850,500 and $250 \mathrm{hPa}$, and the results summed. The analysis fields of the control experiment are used as verification for all calculations. The improvement or reduction of the TE error is defined as the difference of the TE error of the DIAL experiments against the control experiment.

\section{References}

Andersson E, Järvinen H. 1999. Variational quality control. Q. J. R. Meteorol. Soc. 125: 697-722.

Andersson E, Bauer P, Beljaars A, Chevallier F, Hólm E, Janisková M, Kållberg P, Kelly G, Lopez P, McNally A, Moreau E, Simmons AJ, Thépaut JN, Tompkins AM. 2005. Assimilation and modeling of the atmospheric hydrological cycle in the ECMWF forecasting system. Bull. Am. Meteorol. Soc. 86: 387-402.

Andersson E, Hólm E, Bauer P, Beljaars A, Kelly GA, McNally AP, Simmons AJ, Thépaut JN, Tompkins AM. 2007. Analysis and forecast impact of the main humidity observing systems. Q. J. R. Meteorol. Soc. 133: 1473-1485.

Bauer P, Geer A, Lopez P, Salmond D. 2010. Direct 4D-Var assimilation of all-sky radiances. Part I: Implementation. Q. J. R. Meteorol. Soc. 136: $1868-1885$.

Bauer P, Buizza R, Cardinali C, Thépaut JN. 2011. Impact of singularvector-based satellite data thinning on NWP. Q. J. R. Meteorol. Soc. 137: 286-302.

Behrendt A, Wulfmeyer V, Bauer H, Schaberl T, Di Girolamo P, Summa D, Kiemle C, Ehret G, Whiteman DN, Demoz B, Browell EV, Ismail S, Ferrare R, Kooi S, Ehret G, Wang J. 2007a.. Intercomparison of water vapor data measured with lidar during IHOP_2002. Part I: Airborne to ground-based lidar systems and comparisons with chilled-mirror hygrometer radiosondes. J. Atmos. Oceanic Technol. 24: 3-21.

Behrendt A, Wulfmeyer V, Schaberl T, Bauer H, Kiemle C, Ehret G, Flamant C, Kooi S, Ismail S, Ferrare R, Browell EV, Whiteman DN. 2007b.. Intercomparison of water vapor data measured with lidar during IHOP_2002. Part II: Airborne-to-airborne systems. J. Atmos. Oceanic Technol. 24: 22-39.

Bengtsson L, Hodges K. 2005. On the impact of humidity observations in numerical weather prediction. Tellus A 57: 701-708.

Bengtsson L, Hodges K, Hagemann S. 2004. Sensitivity of large-scale atmospheric analyses to humidity observations and its impact on the global water cycle and tropical and extratropical weather systems in ERA40. Tellus A 56: 202-217.

Bhawar R, Di Girolamo P, Summa D, Flamant C, Althausen D, Behrendt A, Kiemle C, Bosser P, Cacciani C, Champollion C, Di Iorio T, Engelmann R, Herold C, Pal S, Wirth M, Wulfmeyer V. 2010. The water vapour intercomparison effort in the framework of the Convective and Orographically-induced Precipitation Study: Airborne-to-ground-based and airborne-to-airborne lidar systems. Q. J. R. Meteorol. Soc., 137: 325-348.

Biswas M, Krishnamurti T. 2008. Adaptive use of research aircraft datasets for hurricane forecasts. Meteorol. Atmos. Phys. 99: 43-64

Bohren CF, Albrecht BA. 1998. Atmospheric thermodynamics. Oxford University Press: New York, NY.

Bösenberg J. 1998. Ground-based differential absorption lidar for water-vapor and temperature profiling: methodology. Appl. Opt. 37: $3845-3860$ 
Browell E, Ismail S, Grant W. 1998. Differential absorption lidar (DIAL) measurements from air and space. Appl. Phys. B 67: 399-410.

Bruneau D, Quaglia P, Flamant C, Meissonnier M, Pelon J. 2001. Airborne lidar LEANDRE II for water-vapor profiling in the troposphere. I. System description. Appl. Opt. 40: 3450-3461.

Cardinali C, Pezzulli S, Andersson E. 2004. Influence-matrix diagnostic of a data assimilation system. Q. J. R. Meteorol. Soc. 130: 2767-2786.

Chou KH, Wu CC, Lin PH, Aberson SD, Weissmann M, Harnisch F, Nakazawa T. 2010. The impact of dropwindsonde observations on typhoon track forecasts in DOTSTAR and T-PARC. Mon. Weather Rev. 139: 1728-1743, DOI:10.1175/2010MWR3582.1.

Desroziers G, Berre L, Chapnik B, Poli P. 2005. Diagnosis of observation, background and analysis-error statistics in observation space. Q. J. R. Meteorol. Soc. 131: 3385-3396.

Ebert E, Damrath U, Wergen W, Baldwin M. 2003. The WGNE assessment of short-term quantitative precipitation forecasts. Bull. Am. Meteorol. Soc. 84: 481-492.

Flentje H, Dörnbrack A, Fix A, Ehret G, Hólm E. 2007. Evaluation of ECMWF water vapour fields by airborne differential absorption lidar measurements: a case study between Brazil and Europe. Atmos. Chem. Phys. 7: 5033-5042.

Gérard É, Tan DGH, Garand L, Wulfmeyer V, Ehret G, Di Girolamo P. 2004. Major advances foreseen in humidity profiling from the water vapour lidar experiment in space (WALES). Bull. Am. Meteorol. Soc. 85: $237-251$.

Healy S, Thépaut J. 2006. Assimilation experiments with CHAMP GPS radio occultation measurements. Q. J. R. Meteorol. Soc. 132: 605-623.

Hock T, Franklin J. 1999. The NCAR GPS dropwindsonde. Bull. Am. Meteorol. Soc. 80: 407-420.

Hólm E, Andersson E, Beljaars A, Lopez P, Mahfouf J, Simmons A, Thépaut J. 2002. 'Assimilation and modelling of the hydrological cycle: ECMWF's status and plans', ECMWF Tech Memo. 383. ECMWF: Reading, UK; 55 pp.

Ismail S, Browell EV. 1989. Airborne and spaceborne lidar measurements of water vapor profiles: a sensitivity analysis. Appl. Opt. 28: 3603-3615.

Järvinen H, Undèn P. 1997. 'Observation screening and background quality control in the ECMWF 3D Var data-assimilation system', ECMWF Tech Memo. 236. ECMWF: Reading, UK; 33 pp.

Kamineni R, Krishnamurti T, Ferrare R, Ismail S, Browell E. 2003. Impact of high-resolution water vapor cross-sectional data on hurricane forecasting. Geophys. Res. Lett 30: 1234. DOI:10.1029/2002GL016741.

Kamineni R, Krishnamurti T, Pattnaik S, Browell E, Ismail S, Ferrare R. 2006. Impact of CAMEX-4 datasets for hurricane forecasts using a global model. J. Atmos. Sci. 63: 151-174.

Keil C, Röpnack A, Craig G, Schumann U. 2008. Sensitivity of quantitative precipitation forecast to height dependent changes in humidity. Geophys. Res. Lett. 35: L09812. DOI:10.1029/2008GL033657.

Kiemle C, Ehret G, Fix A, Wirth M, Poberaj G, Brewer WA, Hardesty RM, Senff C, LeMone MA. 2007. Latent heat flux profiles from collocated airborne water vapor and wind lidars during IHOP_2002. J. Atmos. Oceanic Technol. 24: 627-639.

Kiemle C, Wirth M, Fix A, Ehret G, Schumann U, Gardiner T, Schiller C, Sitnikov N, Stiller G. 2008. First airborne water vapor lidar measurements in the tropical upper troposphere and mid-latitudes lower stratosphere: accuracy evaluation and intercomparisons with other instruments. Atmos. Chem. Phys. 8: 10353-10396.

Marécal V, Gérard É, Mahfouf J, Bauer P. 2001. The comparative impact of the assimilation of SSM/I and TMI brightness temperatures in the ECMWF 4D-Var system. Q. J. R. Meteorol. Soc. 127: 1123-1142.
Marécal V, Mahfouf J, Bauer P. 2002. Comparison of TMI rainfall estimates and their impact on $4 \mathrm{D}-$ Var assimilation. Q. J. R. Meteorol. Soc. 128: 2737-2758.

McNally A. 2002. A note on the occurrence of cloud in meteorologically sensitive areas and the implications for advanced infrared sounders. Q. J. R. Meteorol. Soc. 128: 2551-2556.

Pierrehumbert R. 2002. The hydrologic cycle in deep-time climate problems. Nature 419: 191-198.

Poberaj G, Fix A, Assion A, Wirth M, Kiemle C, Ehret G. 2002. Airborne all-solid-state DIAL for water vapour measurements in the tropopause region: system description and assessment of accuracy. Appl. Phys. B 75: $165-172$.

Poli P, Moll P, Rabier F, Desroziers G, Chapnik B, Berre L, Healy S, Andersson E, El Guelai F. 2007. Forecast impact studies of zenith total delay data from European near real-time GPS stations in Meteo France 4DVAR. J. Geophys. Res. 112: D06114. DOI:10.1029/2006JD 007430.

Rabier F, Jarvinen H, Klinker E, Mahfouf JF, Simmons A. 2000. The ECMWF operational implementation of four-dimensional variational assimilation. I: Experimental results with simplified physics. Q. J. R. Meteorol. Soc. 126: 1143-1170.

Schäfler A, Dörnbrack A, Kiemle C, Rahm S, Wirth M. 2010. Tropospheric water vapor transport as determined from airborne lidar measurements. J. Atmos. Oceanic Technol. 27: 2017-2030.

Sun B, Reale A, Seidel DJ, Hunt DC. 2010. Comparing radiosonde and COSMIC atmospheric profile data to quantify differences among radiosonde types and the effects of imperfect collocation on comparison statistics. J. Geophys. Res 115: D23104. DOI:10.1029/2010JD014457.

Wang, J. 2005. Evaluation of the dropsonde humidity sensor using data from DYCOMS-II and IHOP_2002. J. Atmos. Oceanic Technol. 22: $247-257$.

Wang I, Zhang L, Lin PH, Bradford M, Cole H, Fox J, Hock T, Lauritsen D, Loehrer S, Martin C, VanAndel J, Weng CH, Young K. 2010. Water vapor variability and comparisons in the subtropical Pacific from The Observing System Research and Predictability Experiment-Pacific Asian Regional Campaign (T-PARC) Driftsonde, Constellation Observing System for Meteorology, Ionosphere, and Climate (COSMIC), and reanalyses. J. Geophys. Res 115: D21108. DOI:10.1029/2010JD014494

Weissmann M, Harnisch F, Wu C, Lin P, Ohta Y, Yamashita K, Kim Y, Jeon E, Nakazawa T, Aberson S. 2010. The influence of assimilating dropsonde data on typhoon track and mid-latitude forecasts. Mon. Weather Rev. 139: 908-920, DOI:10.1175/2010MWR3377.1.

Weitkamp C. 2005. Lidar: range-resolved optical remote sensing of the atmosphere, Vol. 102, Springer series in optical sciences. ISSN: $0342-$ 4111. Springer: New York, NY.

Wirth M, Fix A, Mahnke P, Schwarzer H, Schrandt F, Ehret G. 2009. The airborne multi-wavelength water vapor differential absorption lidar WALES: system design and performance. Appl. Phys. B 96 201-213.

Wulfmeyer V, Bösenberg J. 1998. Ground-based differential absorption lidar for water-vapor profiling: assessment of accuracy, resolution, and meteorological applications. Appl. Opt. 37: 3825-3844.

Wulfmeyer V, Bauer HS, Grzeschik M, Behrendt A, Vandenberghe F, Browell EV, Ismail S, Ferrare RA. 2006. Four-dimensional variational assimilation of water vapor differential absorption lidar data: The first case study within IHOP_2002. Mon. Weather Rev. 134: 209-230.

Zus F, Grzeschik M, Bauer H, Wulfmeyer V, Dick G, Bender M. 2008. Development and optimization of the IPM MM5 GPS slant path 4DVAR system. Meteorol. Zeitschrift 17: 867-885. 